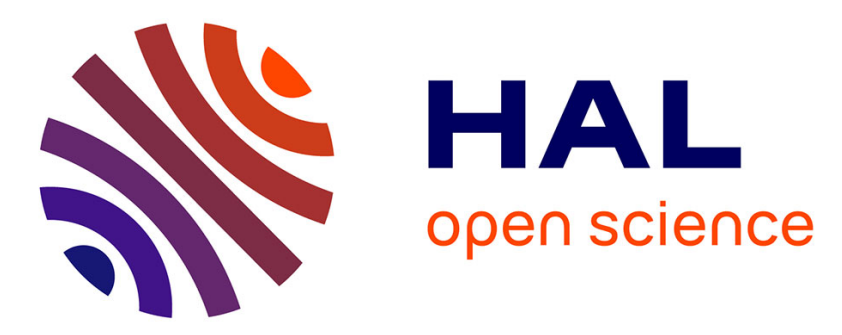

\title{
An attempt to deconstruct the Atlantic Multidecadal Oscillation
}

\author{
Camille Marini, Claude Frankignoul
}

\section{To cite this version:}

Camille Marini, Claude Frankignoul. An attempt to deconstruct the Atlantic Multidecadal Oscillation. Climate Dynamics, 2014, 43 (3-4), pp.607-625. 10.1007/S00382-013-1852-3 . hal-00994608

\section{HAL Id: hal-00994608 \\ https://hal.science/hal-00994608}

Submitted on 21 May 2014

HAL is a multi-disciplinary open access archive for the deposit and dissemination of scientific research documents, whether they are published or not. The documents may come from teaching and research institutions in France or abroad, or from public or private research centers.
L'archive ouverte pluridisciplinaire HAL, est destinée au dépôt et à la diffusion de documents scientifiques de niveau recherche, publiés ou non, émanant des établissements d'enseignement et de recherche français ou étrangers, des laboratoires publics ou privés. 


\title{
An attempt to deconstruct the Atlantic Multidecadal Oscillation
}

\author{
Camille Marini $\cdot$ Claude Frankignoul
}

Received: 21 March 2013/ Accepted: 17 June 2013

(C) Springer-Verlag Berlin Heidelberg 2013

\begin{abstract}
The link between the Atlantic Multidecadal Oscillation (AMO) and low-frequency changes of the Atlantic Meridional Overturning Circulation (AMOC) is investigated in three historical and five control simulations with different climate models. An AMOC intensification is followed by a positive AMO phase in each case, but the time lag and the strength of the AMO-AMOC link depend on the model and the type of simulation. In historical simulations, the link is sensitive to the method used to remove the influence of external and anthropogenic forcing from the sea surface temperature (SST) before defining the AMO. Subtracting the regression onto the global mean SST leads to better correlations between the AMO and the AMOC than linear or quadratic detrending, or removing the global mean SST, but a dynamical filter based on linear inverse modeling (LIM) yields even slightly higher correlations. The LIM filter, which decomposes the SST field into non-orthogonal normal modes that may have a physical interpretation, allows investigating whether removing Pacific links from SST improves the AMOC-AMO correlation. In several cases, there is a small improvement when removing the links to the El Niño Southern Oscillation, but the correlation becomes weaker in one historical simulation, so no firm conclusion can be drawn. Additionally removing the modes associated with the Pacific decadal variability strongly degrades the representation of AMOC changes by the AMO in one model, and it tends to reduce
\end{abstract}

C. Marini $(\bowtie)$

Institut für Meereskunde, Zentrum für Meeres- und

Klimaforschung, Universität Hamburg, Hamburg, Germany

e-mail: camille.marini@zmaw.de

C. Frankignoul

LOCEAN, Université Pierre et Marie Curie, 4 place Jussieu,

75252 Paris Cedex 05, France the AMOC-AMO correlation in most others, reflecting the strong relation between the Pacific and the Atlantic at decadal scales. The LIM-based filter is finally applied to observed SSTs, confirming that the AMO amplitude is smaller and its recent positive phase weaker than when the global effects are represented by a linear trend. When the global signal is removed, the observed AMO leads the Pacific Decadal Oscillation, but does not significantly lag it, as suggested earlier, stressing the need to carefully remove global changes when investigating low-frequency interbasin connections.

Keywords Atlantic Multidecadal Oscillation - Atlantic Meridional Overturning Circulation · Linear inverse modeling · External and anthropogenic forcing · El Niño Southern Oscillation - Pacific decadal variability

\section{Introduction}

The Atlantic Meridional Overturning Circulation (AMOC) is a key component of the climate system, transporting heat northward in the North Atlantic. In most climate models, the AMOC undergoes multidecadal fluctuations that are associated with interhemispheric sea surface temperature (SST) changes (Latif et al. 2004; Vellinga and Wu 2004; Knight et al. 2005; Mignot et al. 2007), which resemble the multidecadal SST variability observed in the North Atlantic, often called the Atlantic Multidecadal Oscillation (AMO) (Kushnir 1994; Kerr 2000; Delworth and Mann 2000). The AMO is commonly implicitly assumed to represent an internal mode of climate variability and is thus defined as the time series of low-pass filtered averaged SST in the North Atlantic after removal of the trend due to anthropogenic and external forcing. The relation between 
the AMOC and the AMO is relevant to climate studies, since there is increasing evidence of AMOC predictability (e.g., Msadek et al. 2010; Matei et al. 2012), and an influence of the AMO on summer precipitation in North America and Europe, Atlantic hurricane activity, and other climatic features has been suggested by several empirical and modeling studies (e.g., Enfield et al. 2001; Sutton and Hodson 2005; Knight et al. 2006). However, the observational record is too short to document the low frequency variability of the AMOC and there is much interest in trying to reconstruct its past variations. In a control simulation of a global climate model, Latif et al. (2004) found a high correlation between low-pass filtered North Atlantic SST anomalies and the AMOC maximum at $30^{\circ} \mathrm{N}$, suggesting that the AMOC variations could perhaps be reconstructed from surface observations. They also showed that, in greenhouse warming simulations, the low-frequency AMOC variability was well reflected in the SST difference between North and South Atlantic. Knight et al. (2005) found a similar correlation in another climate model and suggested that the likely link between the AMO index and the AMOC could be used to attempt reconstructing past variations of the AMOC strength. This was illustrated with the instrumental temperature data, and it could be extended to the proxy-based reconstructions of the SST that are becoming increasingly available (e.g., Mann et al. 2009).

The low-frequency SST variations do not only reflect the AMOC variability, but they are also affected by volcanic activity, solar forcing, and anthropogenic changes (e.g., Otterå et al. 2010; Booth et al. 2012), as well as weather forcing, tropical teleconnections, and ocean dynamics that are not directly related to the AMOC. Hence, there is a need to properly remove these influences before using the AMO as a proxy of AMOC variations. In the historical period, the influence of external and anthropogenic forcing has been traditionally removed by subtracting a linear trend from the AMO index (Enfield et al. 2001; Sutton and Hodson 2005). However, there is no reason to assume that the secular changes vary linearly, and the method would fail in longer climate records. Trenberth and Shea (2006) argued that long-term global changes could be more efficiently removed by subtracting the global mean SST, while Guan and Nigam (2009) used rotated extended empirical orthogonal function (EOF) analysis to remove them, and Enfield and Cid-Serrano (2010) subtracted a quadratic trend. Ting et al. (2009) used regression on the globally averaged SST to remove the anthropogenic and external forcing effects, and they also constructed a modelbased estimate of the forced component of North Atlantic SST variability using several coupled model simulations and a signal-to-noise maximizing EOF analysis. As discussed in this paper, a dynamical filter based on linear inverse modeling (LIM) can also be used to efficiently remove the global effects.

An advantage of the LIM filter, which decomposes a field into non-orthogonal normal modes that may have a physical interpretation, is that it can be used to remove other influences on the AMO that may not reflect the AMOC footprint, such as that due to atmospheric teleconnections associated with the El Niño Southern Oscillation (ENSO) (Alexander et al. 2002; Brönnimann 2007) or Pacific decadal variability (e.g., Enfield and MestasNunez 1999; Guan and Nigam 2009). The impact of the ENSO teleconnections is often removed by linear regression on one or several ENSO indices, but it assumes that these indices properly represent the ENSO dynamics and that their influence is instantaneous or only at a chosen lag in the case of lagged regression. Penland and Matrosova (2006) have shown that LIM can be used to more efficiently subtract the ENSO imprint on the SST field, since the dynamics of tropical SST is well represented by a stable, linear multivariate process driven by stochastic forcing, and the ENSO modes can be identified from the optimal growth from an initial condition to a mature ENSO event. During the course of our study, Compo and Sardeshmukh (2010) used the LIM approach to remove ENSO-related SST variations from the global SST record, albeit in a slightly different manner than done here, finding that the ENSO-unrelated AMO was very close to the traditional one. To remove the Pacific links to the AMO, Guan and Nigam (2009) used a regression of the Atlantic SSTs onto six principal components (PCs) of rotated extended EOFs of Pacific SST. Four PCs corresponded to the ENSO variability, and two to decadal variability: a PanPacific mode and a North Pacific mode linked to the Pacific Decadal Oscillation (PDO), the main mode of SST variability in the North Pacific. This lead to considerable changes in the AMO, mostly because it was correlated with the Pan-Pacific decadal mode (see also Nigam et al. 2011). However, Müller et al. (2008) found a strong coherency at decadal frequencies between the observed PDO and the North Atlantic Oscillation (NAO), which strongly influences the AMOC variability in many oceanic or climate models (e.g., Delworth et al. 1993; Eden and Willebrand 2001; Deshayes and Frankignoul 2008). Hence, it must be established whether removing the North Pacific decadal signal from the AMO improves or degrades its relation to the AMOC.

The aim of this paper is to investigate in historical and control simulations with several climate models whether removing these various influences from the SSTs improves the relation between the AMOC and the AMO. Since the AMOC is known, the efficiency of each approach may be quantified by its maximum correlation with the AMO. Different methods to remove the global effects from the 
AMO are first compared in historical simulations. The LIM filter is then applied to historical and control simulations to investigate whether removing the links to ENSO and decadal Pacific variability improves the representation of the AMOC variability by the AMO. Finally, the LIM filter is applied to the observed SST, and the interest of carefully removing the global SST signal illustrated by discussing the relation between the AMO and the PDO.

LIM assumes that the modes of variability are well represented by stochastically-forced linearized dynamics, which has been found to be approximately valid in many applications (e.g. Penland and Matrosova 1994; Hawkins et al. 2011; Zanna 2012; Newman 2013), but may not always be applicable. Because the eigenmodes are nonorthogonal, the LIM decomposition should, in principle, distinguish better than regression analysis between the externally and anthropogenically forced SST signal and the internal modes of variability that significantly contribute to the global SST average, such as the AMO and the PDO (Meehl and Teng 2012). However, limiting our analysis to SST assumes that the LIM modes are well represented by SST alone. This limitation could be improved upon by including subsurface oceanic data in the analysis, since, for example, they lead to a better representation of the AMOC variability and its impact on the SST in climate models (e.g., Zanna and Tziperman 2005; Hawkins and Sutton 2009), and a better representation of the long-time scale observed behavior of ENSO (Newman et al. 2011). However, we do not aim at establishing how the AMOC variability modulates the SST, as the mechanisms vary between models and may not be representative of the real ocean. For the same reason, we do not attempt to define a SST pattern that would be more representative of the AMOC fluctuations than the AMO. By focusing on the AMO index, which does not depend on the details of the AMOC footprint, we hope to filter out some of the model discrepancies and obtain results that should be general enough to be relevant to the observations and, eventually, the reconstruction of past AMOC variations. Because observations in the ocean interior are limited, subsurface data would be of little use for this purpose, and our analysis is limited to SST data alone.

\section{Data}

The link between the AMO and the AMOC is studied in historical simulations with three climate models, and long control simulations with five climate models. As each model has its own biases, using several models helps to assess the robustness of the results. The historical simulations come from IPSLCM5 (Dufresne et al. 2013), HadCM3 (Gordon et al. 2000), and CCSM3 (Collins et al.
2006). They are forced by solar activity and the atmospheric composition due to anthropogenic and volcanic influences during the period of integration, following the CMIP5 protocol (Taylor et al. 2012) for IPSLCM5 and HadCM3, and the CMIP3 protocol (Meehl et al. 2007) for CCSM3. The control simulations are from IPSLCM4CTRLA (Marti et al. 2010), IPSLCM5-piControl2 (Dufresne et al. 2013), HadCM3 (Gordon et al. 2000), the low-resolution version of MPI-ESM (Jungclaus et al. 2010), and CCSM3 (Collins et al. 2006). For CCSM3, we only consider the last 250 years (yr) of the simulation, when the AMOC has an irregular, red noise-like behavior (Kwon and Frankignoul 2012). The datasets and model resolution are summarized in Table 1. For brevity, model results will be only illustrated for HadCM3, CCSM3, and IPSLCM5. We also consider the HadISST1 SST dataset (Rayner et al. 2003) from 1901 to 2008, which was constructed from in situ SST observations and satellite derived estimates; it will be referred to, for simplicity, as the observations. Note, however, that the amount of observations outside the Atlantic is limited at first, as the data coverage is poor in the North Pacific before around 1946 and in the tropics before around 1960 (Deser et al. 2010).

Throughout this paper, the AMO is the averaged SST in the North Atlantic between 0 and $60^{\circ} \mathrm{N}$, low-passed filtered with a cut-off period $T_{c}=10 \mathrm{yr}$, after removal of the secular changes. Grid points where the sea ice concentration exceeds $20 \%$ in March are omitted from the calculation. The statistical significance of correlations or regressions is given by a student t-test, where the number of degrees of freedom is estimated as in Bretherton et al. (1999). For low-pass filtered data, the time series are sampled for simplicity at half the filter cut-off period

Table 1 Presentation of the models, where 1 indicates level

\begin{tabular}{|c|c|c|c|}
\hline \multirow[t]{2}{*}{ Type } & \multirow[t]{2}{*}{ Duration (year) } & \multicolumn{2}{|l|}{ Resolution } \\
\hline & & Ocean & Atmosphere \\
\hline \multicolumn{4}{|l|}{ HadCM3 } \\
\hline Control & 800 & $288 \times 144,201$ & $96 \times 73,191$ \\
\hline Historical & 146 & & \\
\hline \multicolumn{4}{|l|}{ CCSM3 } \\
\hline Control & 250 & $128 \times 256,401$ & $\mathrm{~T} 85,261$ \\
\hline Historical & 130 & $320 \times 395,401$ & \\
\hline \multicolumn{4}{|l|}{ MPI-ESM } \\
\hline Control & 1,000 & $101 \times 120,401$ & T31, 191 \\
\hline \multicolumn{4}{|l|}{ IPSLCM4 } \\
\hline Control & 1,000 & $182 \times 149,311$ & $96 \times 71,191$ \\
\hline \multicolumn{4}{|l|}{ IPSLCM5 } \\
\hline Control & 1,000 & $182 \times 149,311$ & $96 \times 96,391$ \\
\hline Historical & 156 & & \\
\hline
\end{tabular}


before estimating the effective number of degrees of freedom.

\section{Relation between the AMO and AMOC}

To characterize the AMOC variability at low frequencies, we use two indices, namely the low-pass filtered $\left(T_{c}=10 \mathrm{yr}\right)$ AMOC maximum below $500 \mathrm{~m}$ between $10^{\circ}$ and $60^{\circ} \mathrm{N}$, and the normalized first $\mathrm{PC}$ of similarly filtered AMOC anomalies (hereafter AMOC PC1), whose pattern is a circulation cell spanning the whole Atlantic basin and reaching a maximum between $45^{\circ}$ and $55^{\circ} \mathrm{N}$, depending on the model, as illustrated in Fig. 1. Since the external and anthropogenic forcing does not seem to induce a consistent AMOC response in historical simulations (e.g., Drijfhout et al. 2012), a quadratic trend is simply removed from these indices in all the simulations, to take into account possible model drift due to insufficient spin up of the deep circulation. The AMOC PC1 is illustrated for the last $250 \mathrm{yr}$ of control simulations and the full period of historical simulations in Fig. 2 (left). The traditional AMO, hereafter AMO-trad, which is obtained from linearly detrended SST in grid point space, is given for comparison (dashed line).

An AMOC intensification enhances the northward heat transport in the Atlantic basin (e.g. Dong and Sutton 2001; Latif et al. 2004), resulting in a warming of the North Atlantic that generally projects well onto the AMO in climate models (e.g. Delworth and Mann 2000; Vellinga and
Wu 2004; Knight et al. 2005). The SST modulation by the AMOC is model-dependent, however, as illustrated for 3 control simulations in Fig. 3 by the regression of low-pass filtered $\left(T_{c}=10 \mathrm{yr}\right)$ Atlantic SSTs onto AMOC PC1 when the AMOC leads. For HadCM3 and CCSM3, the SST pattern changes little with lag, with maximum warming along the North Atlantic current. Significant negative anomalies are seen in the northern North Atlantic in CCSM3, but they get smaller as the lag increases. There are more changes with lag in IPSLCM5, reflecting the strong 20-yr oscillation of the subpolar gyre discussed in Escudier et al. (2013), and clearly showing a slow SST advection along the North Atlantic current and into the subpolar gyre (see also Gastineau et al. 2013). In each simulation, the SST footprint of the AMOC at the lag of maximum correlation between AMOC $\mathrm{PC} 1$ and AMO-trad, which depends on the model (Table 2), resembles the AMO pattern (Fig. 4). Note that small positive SST anomalies are also found in the Pacific when regressing the SSTs on the AMOC, suggesting an interbasin link, but they are not shown, as they broadly resemble those associated with the AMO in Fig. 4. The time scales that are important in establishing the AMO-AMOC correlation are shown by the coherence between AMOC PC1 and AMO-trad (Fig. 2, right). The coherence is significant at most periods longer than about $30 \mathrm{yr}$, with very little phase lag. There is also some significant coherence at decadal scales, consistent with the correlation found when the AMO lags the AMOC by a few years.

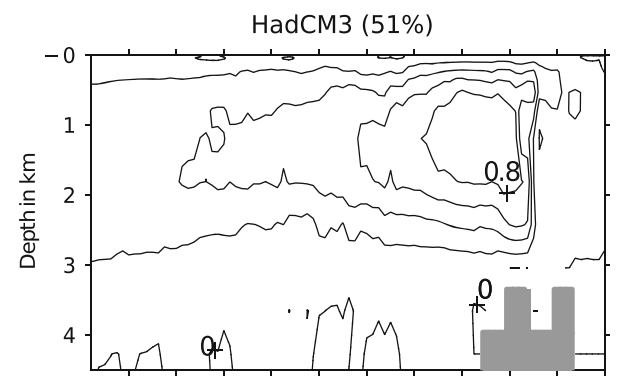

20S IOS 0 ION 2ON 3ON 4ON 5ON 6ON 70N 80N

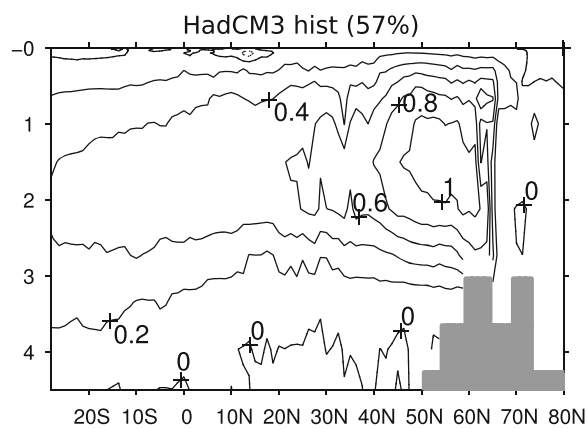

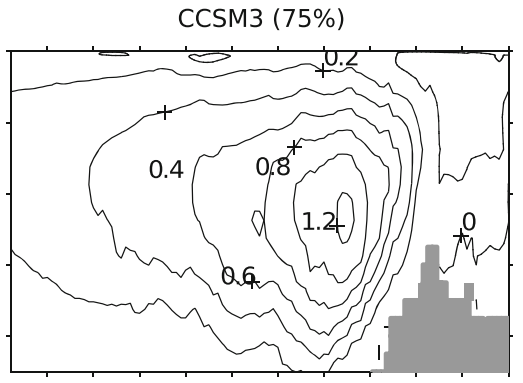

20S 1OS 0 10N 20N 30N 40N 50N 60N 70N 80N

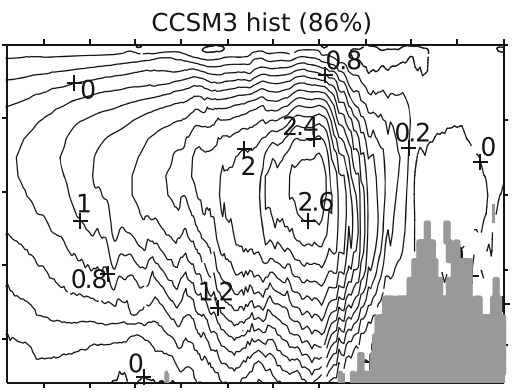

20S IOS 0 ION 2ON 3ON 4ON 50N 6ON 70N 80N

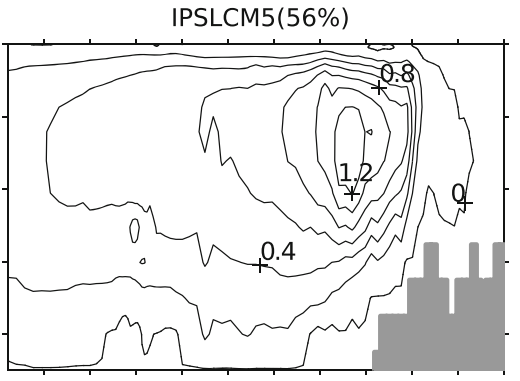

2OS IOS 0 TON 2ON 3ON 4ON 50N 60N 70N 80N

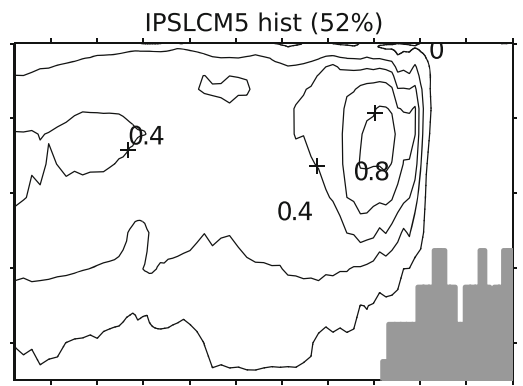

2OS IOS 0 ION 2ON 3ON 4ON 5ON 6ON 70N 80N

Fig. 1 First EOF (in Sv) of low-pass filtered $\left(T_{c}=10 \mathrm{yr}\right.$ ) AMOC anomalies in HadCM3 (left), CCSM3 (middle), and IPSLCM5 (right) for control (top) and historical (bottom) simulations 

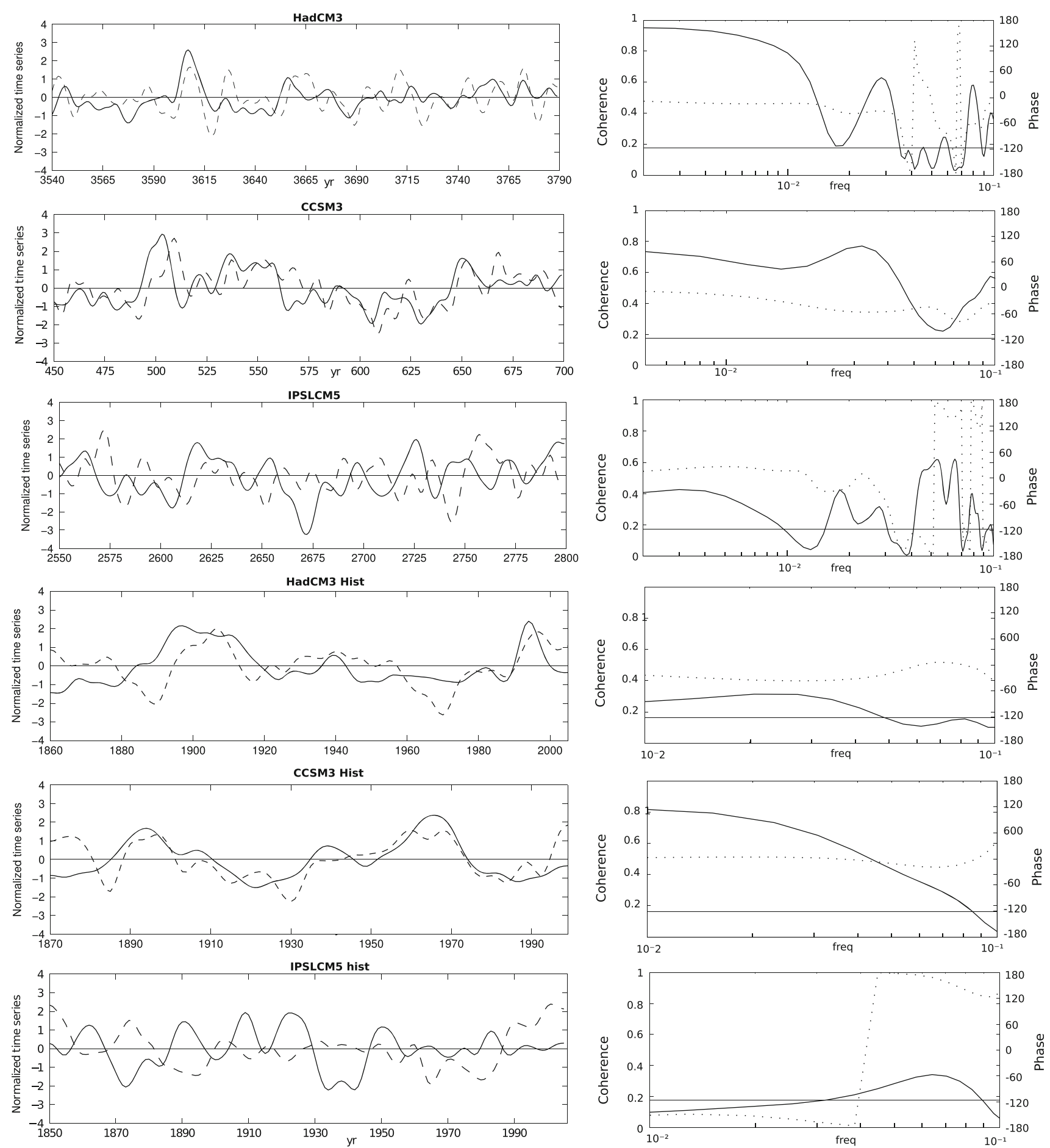

Fig. 2 Left Normalized AMOC PC1 (solid line) and AMO time series (dashed line) in, from top to bottom, control simulations with HadCM3, CCSM3, and IPSLCM5, and historical simulations with the same models. Only the last $250 \mathrm{yr}$ of control simulations are

Broadly similar SST footprints are found in the historical simulations (not shown), but the SST pattern associated with AMO-trad indicates a warming in most oceanic basins (Fig. 5, left panels). In addition, the coherence is smaller in HadCM3 and IPSLCM5 (Fig. 2, right). This represented. Right Coherence spectrum (solid line) and phase (dotted line) between the AMO and AMOC PC1; a Hanning window has been used. The straight line indicates the $10 \%$ significance level

suggests that long-term global SST changes are not well removed from the AMO by a linear trend.

As discussed in Sect. 1, other methods have been used to filter the externally and anthropogenically forced changes from the observed SST before computing the AMO. 
Fig. 3 Regression of low-pass filtered SSTs (in K) onto AMOC PC1 when the AMOC leads by 0,3 and $6 \mathrm{yr}$ for, from top to bottom, HadCM3, CCSM3, and IPSLCM5 control simulations. The black contour indicates $5 \%$ significance and $r$ is the lag correlation between the AMOC PC1 and the AMO. Light gray shading indicates where the sea ice concentration in March is higher than $20 \%$
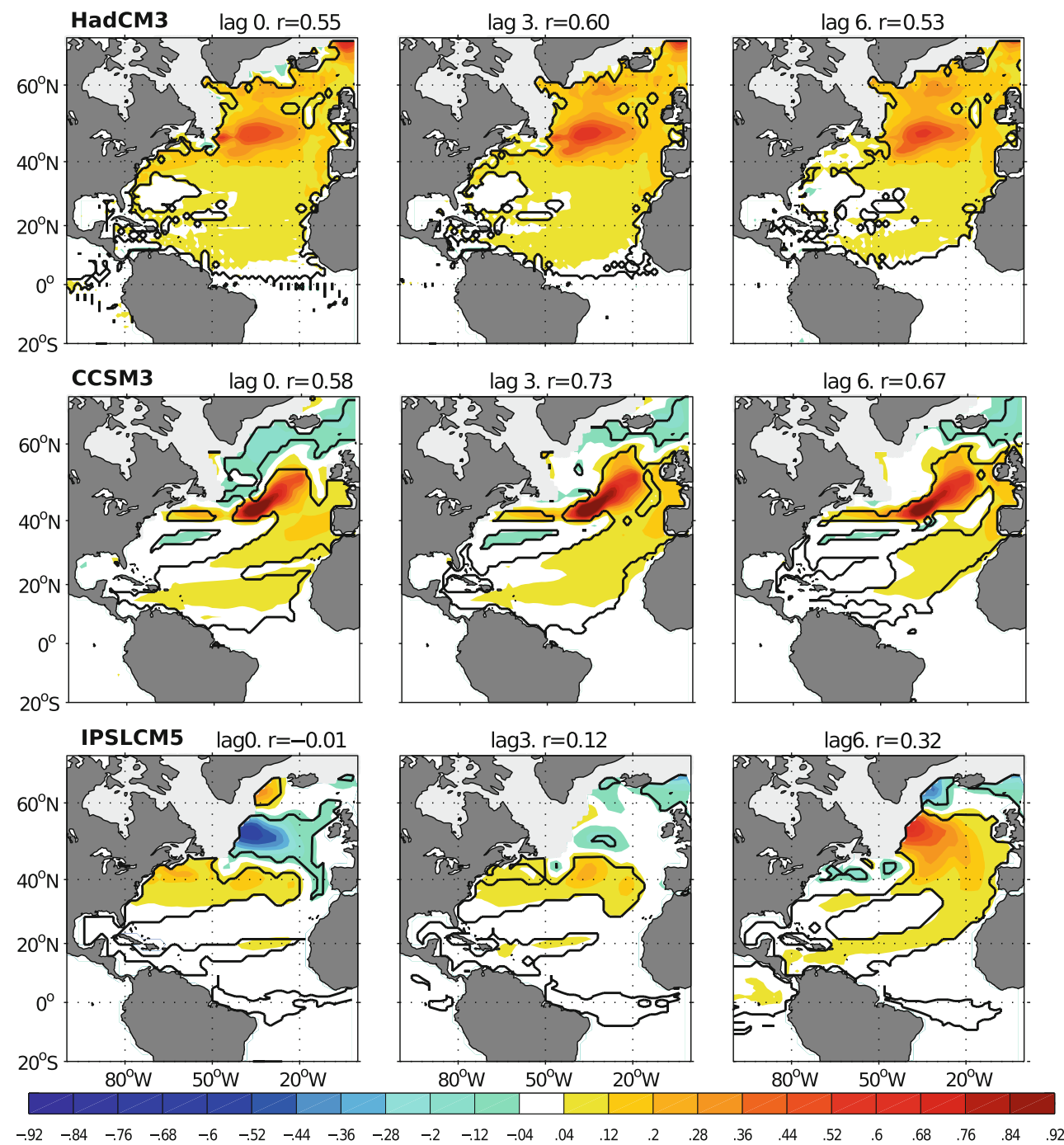

Two data-based methods-removing from each Atlantic grid point the global SST average (Trenberth and Shea 2006) and removing the linear regression on the latter (Ting et al. 2009) - are compared to AMO-trad in Fig. 6 for the historical simulations (black lines). They reduce the AMO amplitude by about $20 \%$ in HadCM3 and CCSM3, and somewhat more in IPSLCM5 where the global warming is strongest. In all cases, the recent warming is less pronounced than with AMO-trad. To quantify the link to the AMOC for each method, the maximum lag correlations between the AMO estimates and the AMOC are given in Table 3. Since the correlations with the two AMOC indices are mostly very similar, for brevity we have only indicated their average value and the averaged lag. Removing a quadratic trend only substantially increases the AMO-AMOC correlation for IPSLCM5, although the increase is not sufficient for the correlation to reach $5 \%$ significance. Removing the global SST average increases the AMO-AMOC correlation in all cases, although the increase is small in HadCM3. Removing a regression on the global SST average further increases the correlation, in particular in HadCM3 and IPSLCM5, suggesting that this method is best, as one would expect from the non-homogeneity of the global mean temperature changes. This is consistent with Ting et al. (2009). In the next section, we use an original method to remove the global mean temperature changes based on LIM.

\section{Using a dynamical filter to deconstruct the AMO}

As discussed in Penland and Matrosova (1994) and Penland and Sardeshmukh (1995), LIM assumes that a variable denoted by $\mathbf{x}$, say SST anomalies, is well approximated by a multivariate linear Markov process

$\frac{d \boldsymbol{x}}{d t}=\boldsymbol{B} \boldsymbol{x}+\boldsymbol{F}$

where $\boldsymbol{B}$ is a linear operator and $\boldsymbol{F}$ a white noise representing the short time scale atmospheric forcing and 
Table 2 Averaged maximum correlation and lag between the various AMO estimates and the AMOC indices in each control simulation

\begin{tabular}{lll}
\hline Model & AMO & Correlation with AMOC \\
\hline HadCM3 control & AMO-trad & $0.61(\operatorname{lag} 2.5)$ \\
& AMO-EN & $0.62(+2 \%)$ \\
& AMO-EN/PD & $0.49(-20 \%)$ \\
CCSM3 control & AMO-trad & $0.66(\operatorname{lag} 3)$ \\
& AMO-EN & $0.66(0 \%)$ \\
& AMO-EN/PD & $0.62(-6 \%)$ \\
MPI-ESM control & AMO-trad & $0.29(\operatorname{lag} 3)$ \\
& AMO-EN & $0.32(+10 \%)$ \\
& AMO-EN/PD & $0.30(+3 \%)$ \\
IPSLCM4 control & AMO-trad & $0.38(\operatorname{lag} 6.5)$ \\
& AMO-EN & $0.40(+5 \%)$ \\
& AMO-EN/PD & $0.40(+5 \%)$ \\
IPSLCM5 control & AMO-trad & $0.40(\operatorname{lag} 8.5)$ \\
& AMO-EN & $0.43(+8 \%)$ \\
\hline
\end{tabular}

The percentage indicates the increase in correlations when using modified AMO indices compared with AMO-trad

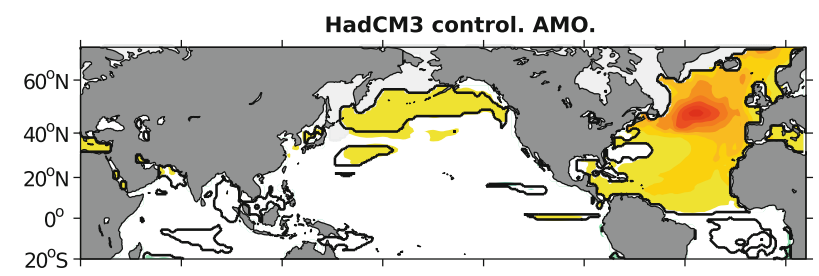

CCSM3 control. AMO.
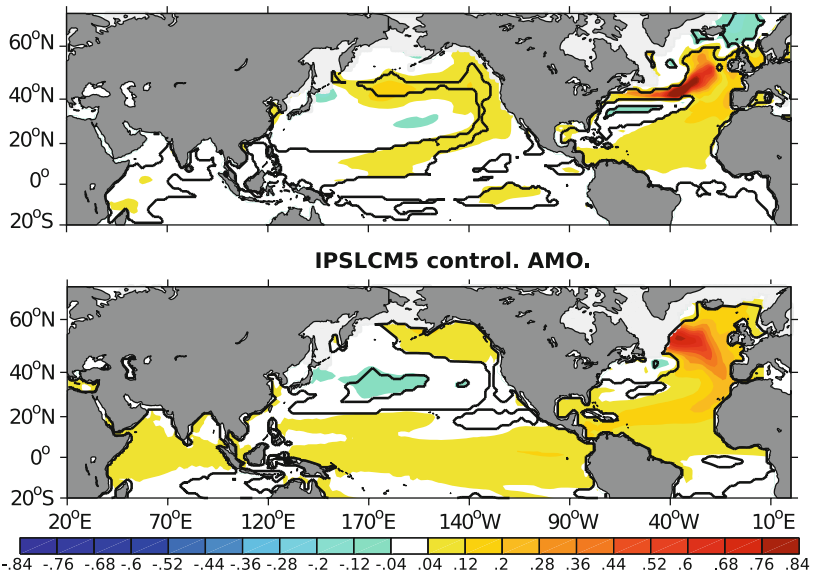

Fig. 4 SST pattern (in K) associated with the AMO in control simulations. From top to bottom: HadCM3, CCSM3, and IPSLCM5. The black contour indicates $5 \%$ significance

decorrelated nonlinear processes. It is assumed to be a Gaussian white noise with constant covariance matrix $\boldsymbol{Q}=\left\langle\boldsymbol{F}^{T} \boldsymbol{F}\right\rangle$, where the subscript $T$ indicates transpose. The dimensionality of the system is conveniently reduced by working in a truncated EOF space, meaning that $\boldsymbol{x}$ contains the main PCs of the SST anomalies. A solution of (1) is: $\boldsymbol{x}(\tau)=e^{\tau \boldsymbol{B}} \boldsymbol{x}(0)+\varepsilon(\tau)$

where $\boldsymbol{G}(\tau)=e^{\tau \boldsymbol{B}}$ is the linear propagator and $\varepsilon(\tau)$ the prediction error. The matrix $\boldsymbol{B}$ can be empirically derived from

$\boldsymbol{B}=\tau^{-1} \ln \left(\boldsymbol{C}(\tau) \boldsymbol{C}(0)^{-1}\right)$

where $\boldsymbol{C}(\tau)$ is the covariance matrix of $\boldsymbol{x}$ at lag $\tau$. Based on (2), an eigenanalysis of $\boldsymbol{B}$ leads to writing $\boldsymbol{x}(t)$ as a sum of empirical normal modes,

$\boldsymbol{x}(t)=\sum_{i} \boldsymbol{u}_{i} \alpha_{i}(t)$

where $\boldsymbol{u}_{i}$ is the eigenvector of $\boldsymbol{B}$ associated with the eigenvalue $\beta_{i}$, and $\alpha_{i}(t)$ the time series obtained by projecting $\boldsymbol{x}$ onto the corresponding adjoint eigenvector. As $\boldsymbol{B}$ is a real, but not a symmetric matrix, the eigenmodes may be nonorthogonal and the eigenvalues complex conjugates. As $\boldsymbol{B}$ is definite and negative, all its eigenvalues have negative real parts. The $i$ th eigenmode of $\boldsymbol{B}$ is thus either a stationary damped mode (real $\beta_{i}$ ) or an oscillatory damped mode (complex $\beta_{i}$ ). Each damped eigenmode is characterized by one pattern, one time series, and a decay time $-1 / \operatorname{Re}\left(\beta_{i}\right)$. Each oscillatory mode is described by two patterns and two time series corresponding to the cosine and sine phases, a time period $2 \pi / \operatorname{Im}\left(\beta_{i}\right)$, and a decay time.

Here we use LIM to decompose the global SST field into non-orthogonal normal modes, and we identify modes that correspond to global mean temperature changes, ENSO variability, and other processes that could influence the North Atlantic SSTs and thus deteriorate the link between the AMO and the AMOC. Once these modes are identified, the SST field can be decomposed into a sum of various parts, which may not be independent. These parts can be subtracted, as done for ENSO modes in Penland and Matrosova (2006), and a "filtered" AMO can be computed from the residual SST (again as the time series of low-pass filtered averaged SST in the North Atlantic). Because LIM represents the space-time behavior of modes that may have a physical interpretation without assuming orthogonality between them, LIM should distinguish well between modes of variability with different dynamics, as successfully illustrated for example for seasonal tropical SST anomalies (e.g. Penland and Matrosova 1994), wintertime extratropical atmospheric variability (Newman and Sardeshmuck 2008), yearly Atlantic temperature anomalies (Hawkins et al. 2011; Zanna 2012), and yearly global surface temperature anomalies (Newman 2013). Hence, the LIM-based filter should be a more dynamically consistent method to filter out a signal than linear regression on an index, since the latter only removes the pattern identified by an index that may not represent the whole dynamics of the signal. Nevertheless, it should be noted that this approach assumes 


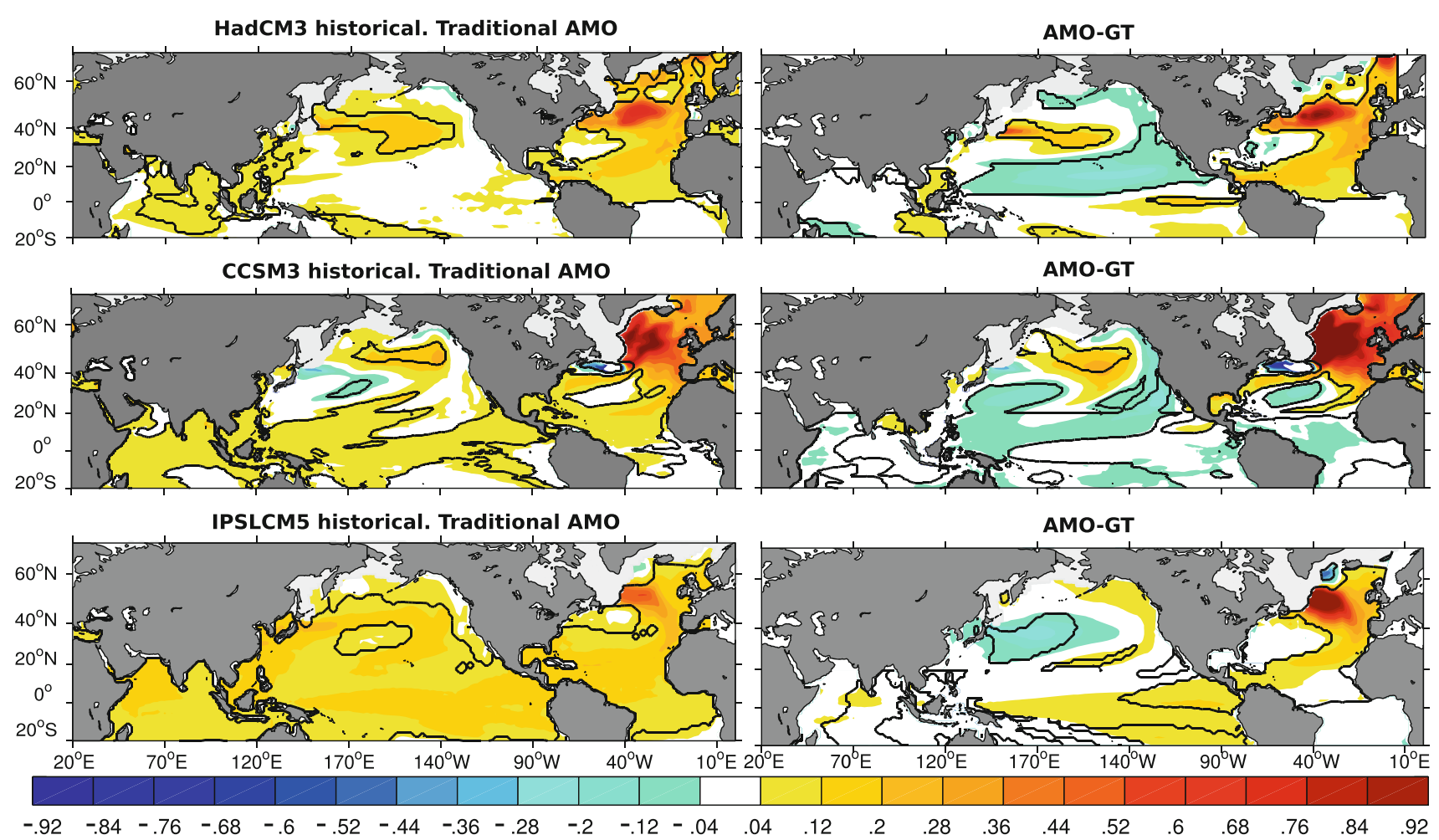

Fig. 5 SST pattern (in K) associated with AMO-trad (left) and AMO-GT (right) in historical simulations. From top to bottom: HadCM3, CCSM3, and IPSLCM5. The black contour indicates $5 \%$ significance

that the dynamics of the space in which we are working is linear, and thus some modes of variability may not be fully represented. Here we use seasonal SST anomalies between $20^{\circ} \mathrm{S}$ and about $70^{\circ} \mathrm{N}$. To reduce the dimensionality of the system and to eliminate small-scale noise in the data, we work in a truncated EOF space, which is defined separately in 3 different domains: the North Atlantic $\left(20^{\circ}-70^{\circ} \mathrm{N}\right.$, $\left.100^{\circ} \mathrm{W}-5^{\circ} \mathrm{E}\right)$, the North Pacific $\left(20^{\circ}-70^{\circ} \mathrm{N}, 120^{\circ} \mathrm{E}-\right.$ $\left.100^{\circ} \mathrm{W}\right)$, and the tropical strip $\left(20^{\circ} \mathrm{S}-20^{\circ} \mathrm{N}\right)$. Hence, the state vector $\mathbf{x}$ is composed of three sets of PCs. About $70 \%$ of the variance is retained in each three domains, and it was verified that the results depend little on the EOF truncation. As the matrix $\boldsymbol{B}$ could only be determined at a lag of one season, probably because of the Nyquist problem at larger lags, ${ }^{1}$ we use the test of Winkler et al. (2001) to verify the applicability of the LIM approach, as described in Appendix 1.

The temporal characteristics of the main eigenmodes in the historical simulations are listed in Table 4. They are shown in Fig. 7 for IPSLCM5, where the first mode is a damped non-oscillatory mode that represents a global warming, as its associated time series has a strong positive trend. This also holds for HadCM3, while in CCSM3 the

\footnotetext{
1 If 3-month running mean anomalies had been used, lags from 1 to 4 months could be used.
}

warming trend is represented by the second mode (Fig. 8). The correlation of these modes with the global SST average is 0.7 in CCSM3, 0.9 in HadCM3, and 0.95 in IPSLCM5, and no other mode shows such a pronounced trend. The mode pattern differs somewhat between the models, but it always shows a pronounced warming in the tropical Pacific and the North Atlantic. Note that this mode may still contain some low-frequency variability that is unrelated to the warming trend, due to the limited length of data. The other eigenmodes vary between models, but there are also similarities, in particular there are always several ENSO modes and a multidecadal oscillatory mode with strong anomalies in the subpolar North Atlantic and a PDO-like pattern in the North Pacific. Similar results (without the global warming mode) are found for the control simulations.

\subsection{Removing the global trend in the historical simulations}

After subtracting the global warming modes from the SSTs in the historical simulations, a "filtered" AMO, referred to as AMO-GT, was computed from the SST residual by applying the low-pass filter, without detrending the data. As shown in Fig. 6 (red line), its amplitude is generally smaller than the traditional AMO, as with the other 
Fig. 6 AMO (in K) when the global changes are removed with a linear trend (AMO-trad, solid line), by subtracting the global SST average (dotted) or the regression onto the global SST average (dashed), and using LIM (AMO-GT, thick red line) in, from top to bottom, the historical simulation with IPSLCM5, and the observations $\mathrm{HadCM} 3, \mathrm{CCSM} 3$, and
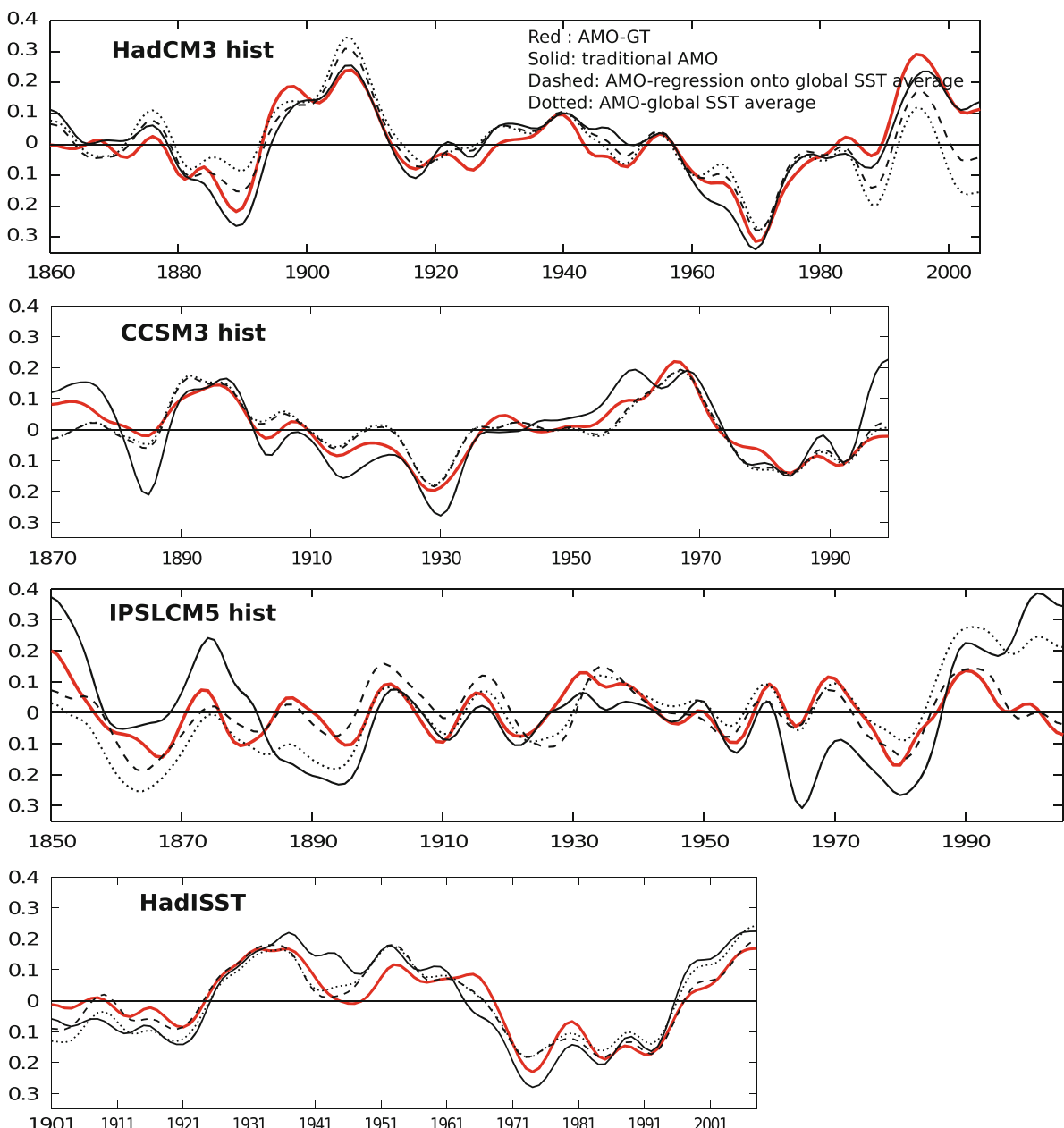

methods, but there are differences in the AMO evolution. The SSTs associated with AMO-GT (Fig. 5 right) indicate less warming than with AMO-trad, except in the subpolar North Atlantic, where the SST maximum is stronger. There are also regions with weak cooling in the Pacific. As shown in Table 3, the correlation between the AMOC and AMOGT is substantially larger than with AMO-trad in each model, with an averaged increase reaching $87 \%$ for IPSLCM5, and it tends to occur at a slightly shorter lag. The correlation is $16 \%$ higher in HadCM3 than when the AMO is corrected using the regression onto the global SST average, slightly larger in IPSLCM5, and the same in CCSM3. Hence, LIM might be most efficient at removing the global temperature changes from the AMO, based on the historical simulations considered in this study.

\subsection{Removing the ENSO signal}

As described in Appendix 2, a subset $E$ of ENSO modes is identified in each historical simulation (bold letters in Table 4). These modes may be additionally subtracted from the SST residual above, yielding an ENSO-unrelated AMO, referred to as AMO-GT/EN. Removing the ENSO modes changes little the AMO behavior, and AMO-GT and AMO-GT/EN are highly correlated. Nonetheless, the averaged correlation of AMO-GT/EN with the AMOC is smaller by $15 \%$ than with AMO-GT in HadCM3, almost unchanged in CCSM3, and increased by $12 \%$ in IPSLCM5, and it occurs at a slightly longer lag (Table 3). Because of this model dependence, which might reflect different links between ENSO and the external and anthropogenic forcing, no firm conclusion can be drawn.

To further investigate the impact of ENSO removal, the SST field in each control simulation was similarly decomposed into LIM modes, and ENSO modes identified and subtracted. The evolution of the resulting AMO (AMO-EN) is very similar to AMO-trad in HadCM3, MPIESM, and CCSM3 ( $r \geq 0.93$ ), but the ENSO removal has a stronger impact in IPSLCM4 $(r=0.79)$ and IPSLCM5 $(r=0.85)$. The AMO patterns remain similar in the northern North Atlantic, but the interhemispheric pattern in the Atlantic is reinforced in IPSLCM5 and HadCM3, and there are significant changes in the Pacific, in particular an equatorial warming in CCSM3 and in IPSLCM5 (not shown). As shown in Table 2, ENSO removal slightly increases the AMO-AMOC correlation in MPI-ESM and 
the two IPSL models, while affecting it little in HadCM3 and CCSM3. Yet, overall there is no compelling evidence that the ENSO links should be removed.

\subsection{Removing the link with the Pacific decadal variability}

Several studies indicate a strong link between low frequency variability in the North Atlantic and the Pacific

Table 3 Averaged maximum correlation between the various AMO estimates and the two AMOC indices in each historical simulation

\begin{tabular}{lll}
\hline Model & AMO & Correlation with AMOC \\
\hline HadCM3 historical & AMO-trad & 0.54 (lag3) \\
& AMO-detQuadra & $0.54(\operatorname{lag} 3) 0 \%$ \\
& AMO-SSTg & $0.57(\operatorname{lag} 1.5)+6 \%$ \\
& AMO-regSSTg & $0.61(\operatorname{lag} 2)+13 \%$ \\
& AMO-GT & $0.71(\operatorname{lag} 1.5)+31 \%$ \\
& AMO-GT/EN & $0.60(\operatorname{lag} 2)+11 \%$ \\
CCSM3 historical & AMO-GT/EN/PD & $0.36(\operatorname{lag}-1)-33 \%$ \\
& AMO-trad & $0.68(\operatorname{lag} 1.5)$ \\
& AMO-detQuadra & $0.71(\operatorname{lag} 3)+4 \%$ \\
& AMO-SSTg & $0.82(\operatorname{lag} 1)+21 \%$ \\
& AMO-regSSTg & $0.83(\operatorname{lag} 1)+22 \%$ \\
& AMO-GT & $0.83(\operatorname{lag} 1.5)+22 \%$ \\
& AMO-GT/EN & $0.84(\operatorname{lag} 2.5)+24 \%$ \\
& AMO-GT/EN/PD & $0.85(\operatorname{lag} 1)+25 \%$ \\
AMSLCM5 historical & AMO-trad & $0.23(\operatorname{lag} 11)$ \\
& AMO-detQuadra & $0.28(\operatorname{lag} 11)+22 \%$ \\
& AMO-SSTg & $0.27(\operatorname{lag} 10)+17 \%$ \\
& AMO-regSSTg & $0.40(\operatorname{lag} 10)+74 \%$ \\
& AMO-GT & $0.43(\operatorname{lag} 9)+87 \%$ \\
AMO-GT/EN & $0.48(\operatorname{lag} 10)+109 \%$ \\
& AMO-GT/EN/PD & $0.41(\operatorname{lag} 9)+78 \%$ \\
\hline
\end{tabular}

Italic indicates that the correlation is not $5 \%$ significant (e.g. Zhang and Delworth 2007; Dima and Lohmann 2007; Li et al. 2009). Orgeville and Peltier (2007) found in the observations a strong correlation between the AMO and the multidecadal component of the PDO when the AMO leads or lags by $13 \mathrm{yr}$, arguing that these signals were the two components in phase quadrature of a unique oscillation cycle. Using a statistical method maximizing integral time scale in climate models and the observations, DelSole et al. (2011) identified an unforced internal component varying at multidecadal time scales and showing a strong amplitude in both North Atlantic and Pacific. They indicated that these multidecadal North Atlantic and Pacific signals are covarying structures. Guan and Nigam (2009) suggested that the Pacific was influencing the Atlantic and obtained a very different $\mathrm{AMO}$ by removing the signals linked to Pacific decadal variability in the observations, primarily because their Pan-Pacific decadal mode lead the AMO by 5 seasons. However, Müller et al. (2008) showed that there was a significant coherence in the observations at periods of 10-20 yr between the NAO, ENSO, the Aleutian low, and the PDO, suggesting global atmospheric teleconnections that may be driven by the North Pacific. As the NAO is a main driver of the AMOC variability in many models, including HadCM3 and CCSM3 (Dong and Sutton 2005; Kwon and Frankignoul 2012), removing such interbasin teleconnections from the AMO could degrade its relation to the AMOC.

To test the influence of the Pacific decadal variability links, we attempted to identify in each model eigenmodes with a strong low frequency signal in the North Pacific. The Pacific decadal modes are chosen as having a period larger than $10 \mathrm{yr}$ (or showing strong decadal changes if the mode is only damped), a large amplitude in the Pacific, and some links to the low-pass filtered $\left(T_{c}=10 \mathrm{yr}\right)$ PDO (the first North Pacific SST EOF), since the PDO is the main mode of decadal variability in the Pacific. Between 1 and 3

Table 4 Decay times (DT) and periods (T) of the first B eigenmodes for the 3 historical simulations and the observations

\begin{tabular}{|c|c|c|c|c|c|c|c|c|c|c|c|}
\hline \multicolumn{3}{|c|}{ HadCM3 historical } & \multicolumn{3}{|c|}{ CCSM3 historical } & \multicolumn{3}{|c|}{ IPSLCM5 historical } & \multicolumn{3}{|c|}{ Observations } \\
\hline Mode & $D T$ (month) & $T(\mathrm{yr})$ & Mode & $D T$ (month) & $T(\mathrm{yr})$ & Mode & $D T$ (month) & $T(\mathrm{yr})$ & Mode & $D T$ (month) & $T(\mathrm{yr})$ \\
\hline 1 & $4 \mathrm{yr}$ & $\infty$ & 1 & $9 \mathrm{yr}$ & $\infty$ & 1 & $10.3 \mathrm{yr}$ & $\infty$ & 1 & $4.3 \mathrm{yr}$ & $\infty$ \\
\hline $2 / 3$ & $2.1 y r$ & 122 & 2 & $6 \mathrm{yr}$ & $\infty$ & 2 & $1.3 \mathrm{yr}$ & $\infty$ & $2 / 3$ & $1.6 y r$ & $47.7 y r$ \\
\hline $4 / 5$ & $1.7 y r$ & 21 & $3 / 4$ & $1.8 \mathrm{yr}$ & 77 & $3 / 4$ & 11 month & $5 \mathrm{yr}$ & 4 & $1.1 y r$ & $\infty$ \\
\hline 6 & $1.3 \mathrm{yr}$ & $\infty$ & $5 / 6$ & $1.4 y r$ & 16.5 & 5 & 9 month & $\infty$ & $5 / 6$ & 10 month & $7.2 \mathrm{yr}$ \\
\hline $7 / 8$ & $1.2 y r$ & 8.7 & $7 / 8$ & $1.2 \mathrm{yr}$ & 2.4 & $6 / 7$ & 7 month & $13.8 y r$ & $7 / 8$ & 7 month & $3.1 \mathrm{yr}$ \\
\hline $9 / 10$ & $1.1 \mathrm{yr}$ & 4.4 & 9 & $1 \mathrm{yr}$ & $\infty$ & 8 & 6 month & $\infty$ & $9 / 10$ & 6 month & $13.1 \mathrm{yr}$ \\
\hline $11 / 12$ & $1.1 \mathrm{yr}$ & 2.6 & $10 / 11$ & 9 & 20.4 & $9 / 10$ & 6 month & $6.6 \mathrm{yr}$ & 11 & 6 month & $\infty$ \\
\hline $13 / 14$ & $1 \mathrm{yr}$ & 20 & $12 / 13$ & 8 & 8 & $11 / 12$ & 5 month & $20 \mathrm{yr}$ & $12 / 13$ & 5 month & $4.7 \mathrm{yr}$ \\
\hline $15 / 16$ & 10 & 10 & $14 / 15$ & 7 & 19.6 & $13 / 14$ & 5 month & $2.4 \mathrm{yr}$ & $14 / 15$ & 4 month & $14.4 \mathrm{yr}$ \\
\hline $17 / 18$ & 9 & 5.4 & $16 / 17$ & 6 & 4.9 & $22 / 23$ & 3 month & $2.8 \mathrm{yr}$ & $16 / 17$ & 4 month & $3.4 \mathrm{yr}$ \\
\hline
\end{tabular}

The ENSO modes are indicated in bold characters, and the Pacific decadal modes in italics 

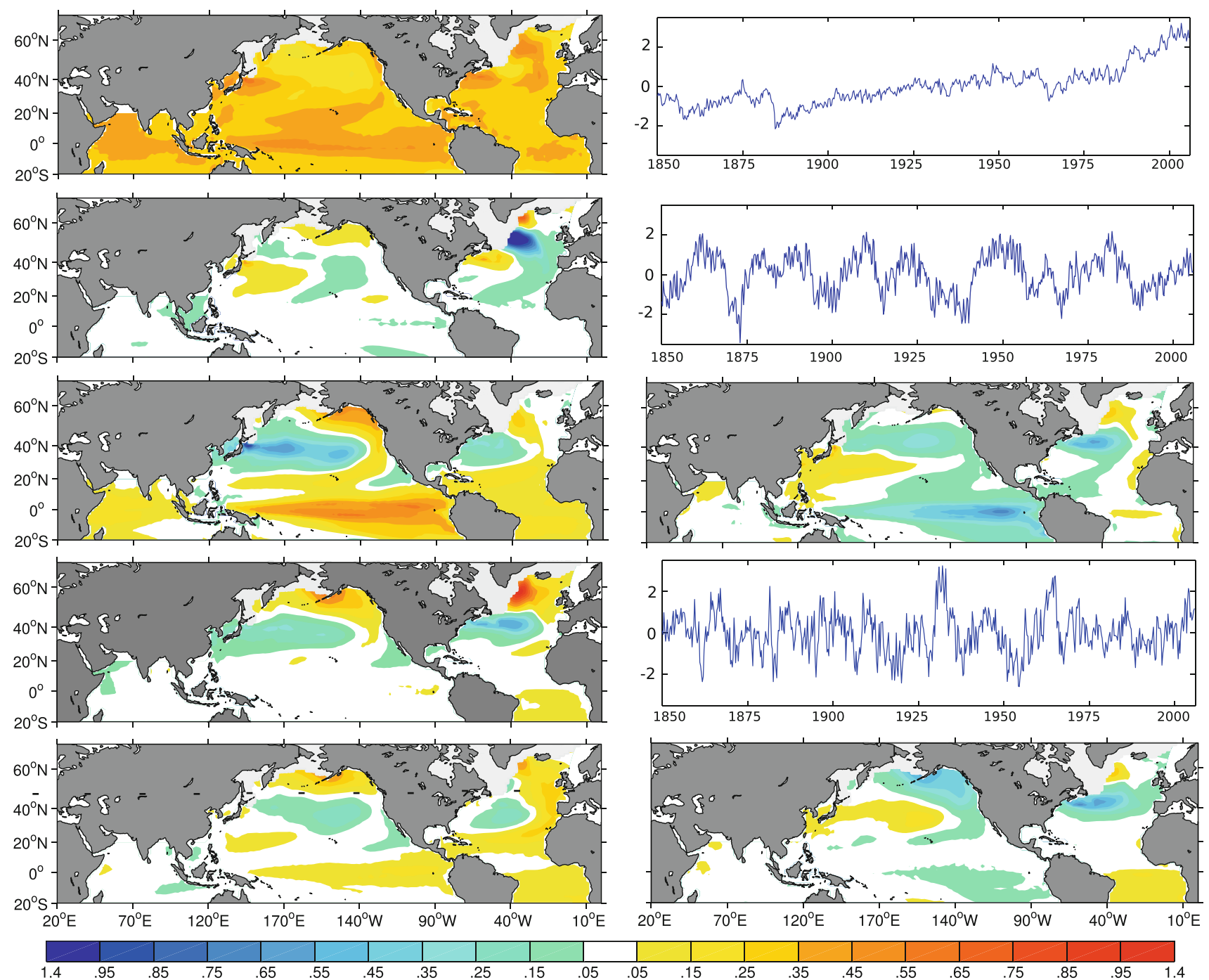

Fig. 7 Normal modes of the deterministic matrix $\boldsymbol{B}$ number, from top to bottom, 1, 2, 3/4, 5, and 6/7 for the historical IPSLCM5 simulation. The time series of the non-oscillatory modes is represented

modes were selected (see Table 4 for the historical simulations), except that no mode corresponded to our criteria in the IPSLCM5 control simulation. This selection is somewhat subjective, but similar results were found when using additional modes. Perhaps because our domain is limited to $20^{\circ} \mathrm{S}$, the selected modes largely represent the low-frequency behavior of the PDO, as the PDO reconstructed from them compares rather well to the traditional one, with a temporal correlation at low frequency of about 0.7 , except 0.91 in CCSM3. As illustrated for the IPSLCM5 historical simulation in Fig. 7 (bottom two rows), the Pacific decadal modes also have a substantial amplitude in the North Atlantic. Hence, removing these modes from the SST field may strongly modify the low-frequency variability of the AMO, as in the observations.

To quantify their impact on the AMO-AMOC correlations, the decadal Pacific modes were added to the subset of already removed modes and a filtered AMO was computed, referred to as AMO-EN/PD in control simulations and AMO-GT/EN/PD in historical ones. As shown in Tables 2 and 3, the correlation with the AMOC indices is strongly degraded in HadCM3 as compared to AMO-EN and AMO-GT/EN, slightly reduced in MPI-ESM, the control CCSM3, and the historical IPSLCM5 simulations, while changing little in the 3 other cases. In the historical simulations, the lag of maximum correlation also tends to be smaller, and AMO even leads the AMOC in HadCM3. Despite the model-dependence, the results suggest that the signals linked to the Pacific decadal variability, at least as we identified them, should not be subtracted from the AMO if its relation to the AMOC is to be optimized.

However, it should be pointed out that the models may not reproduce the North Pacific decadal variability very well, even though HadCM3 shows good skills at simulating 


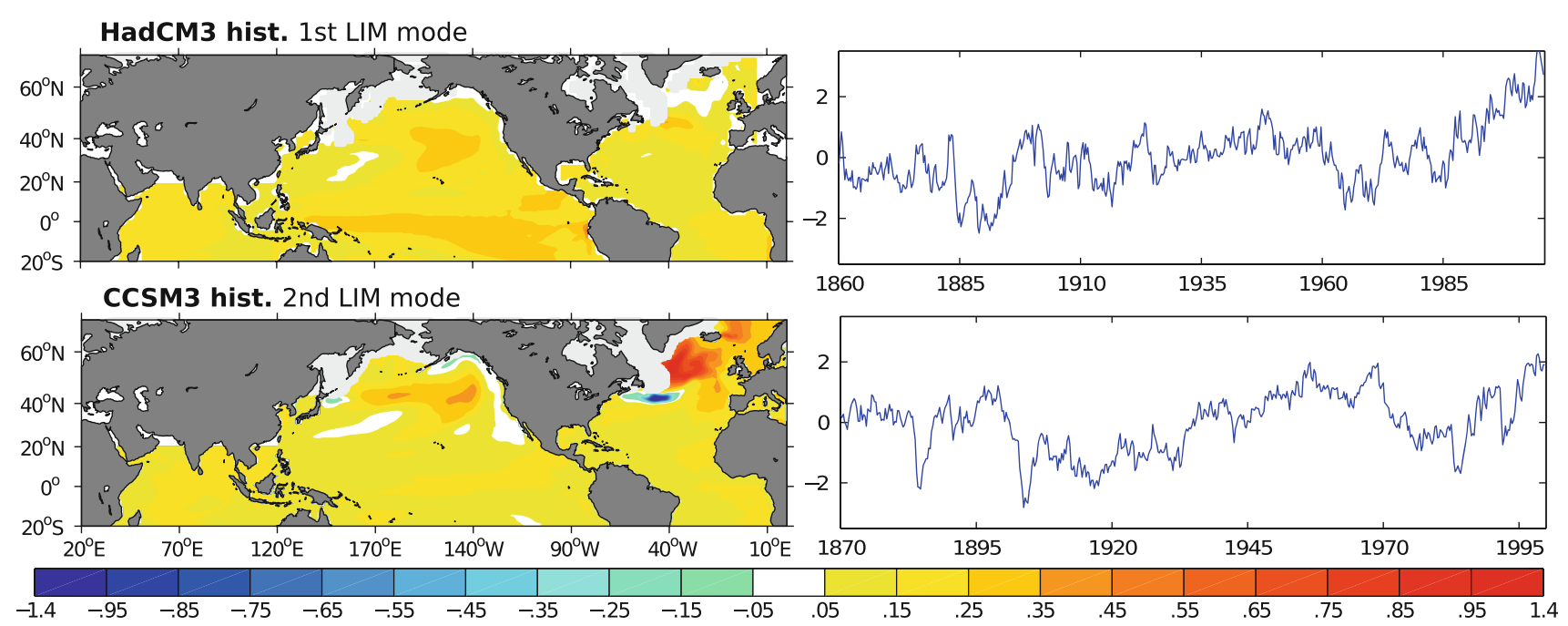

Fig. 8 Normal mode of the deterministic matrix $\boldsymbol{B}$ corresponding to global changes in the historical simulation with HadCM3 (top) and CCSM3 (bottom)

the PDO in 20th century simulations (Overland and Wang 2007; Oshima and Tanimoto 2009; Furtado et al. 2011). In addition, the atmospheric teleconnections and the coupling between the decadal SST variability of the two basins may be misrepresented. As shown in Fig. 9 for control simulations, the low-pass filtered PDO is associated with the Aleutian low in each model, as in the observations (represented here by the HadSLP2 dataset for 1901-2008 (Allan and Ansell 2006)), but it is also unrealistically associated with a strong Arctic high, which leads in particular to a negative NAO phase in CCSM3 and the IPSL models. Nonetheless, the models reproduce the lack of simultaneous correlation that is observed between the AMO and PDO (Orgeville and Peltier 2007, see also below), except in IPSLCM5 where the correlation reaches 0.27 . On the other hand, the lead and lag correlations vary between models and do not resemble the observed ones (not shown).

\section{The AMO in the observations}

The LIM deconstruction was similarly applied to the SST observations. The domain of our analysis is limited to $60^{\circ} \mathrm{N}$ because of poorer data quality further north. Note that the amount of observations in the first half of the record is limited outside the Atlantic, which might be an issue when looking at other basins. The $\boldsymbol{B}$ eigenmodes are listed in Table 4 (right), and the first 8 patterns are shown in Fig. 10. As in most historical simulations, the least damped mode primarily represents the secular SST signal $(0.95$ correlation with the globally averaged SST), although the time series also has shorter variations. The SST pattern shows a strong warming in the western North Atlantic, along the rim of the North Pacific, and the eastern coast of the Atlantic, with only weak warming in the tropical and central North Pacific. This is broadly consistent with the secular trend estimated from rotated extended EOF of Pacific SST in Guan and Nigam (2009) and from the model-based forced component of North Atlantic SST variability in Ting et al. (2009) and DelSole et al. (2011). Note that the long-term global change signal differs from that in the historical simulations, with a weaker amplitude than in IPSLCM5, suggesting that the model overestimates the response to external and anthropogenic forcing. Interestingly, Newman (2013) constructed a LIM from global observed SST, albeit in a similar way as done here, except that he used yearly anomalies, did not limit the analysis to $20^{\circ} \mathrm{S}-60^{\circ} \mathrm{N}$, and included observed surface air temperature. The resulting LIM modes show strong similarities with our analysis; the least damped mode is notably stationary and corresponds to the secular trend. Its pattern resembles the pattern of our mode 1, except for a cooling in the tropical eastern Pacific.

The time evolution of the "filtered" AMO, AMO-GT, obtained by removing mode 1 , shows significant differences with the other AMO estimates (Fig. 6 bottom). Although the warm and cold phases are similar, its standard deviation is smaller than that of AMO-trad (0.11 vs. $0.14^{\circ} \mathrm{C}$ ), and the recent warming is less pronounced, as in Trenberth and Shea (2006) and Enfield and Cid-Serrano (2010). The associated SST patterns are similar, although AMO-GT has a small area of negative anomalies south of Newfoundland, and there are no anomalies in the North Pacific and weaker ones in the tropical Pacific (Fig. 11).

The other eigenmodes do not correspond one by one to those of the historical simulations, reflecting the small sample and the limited realism of the models, although 

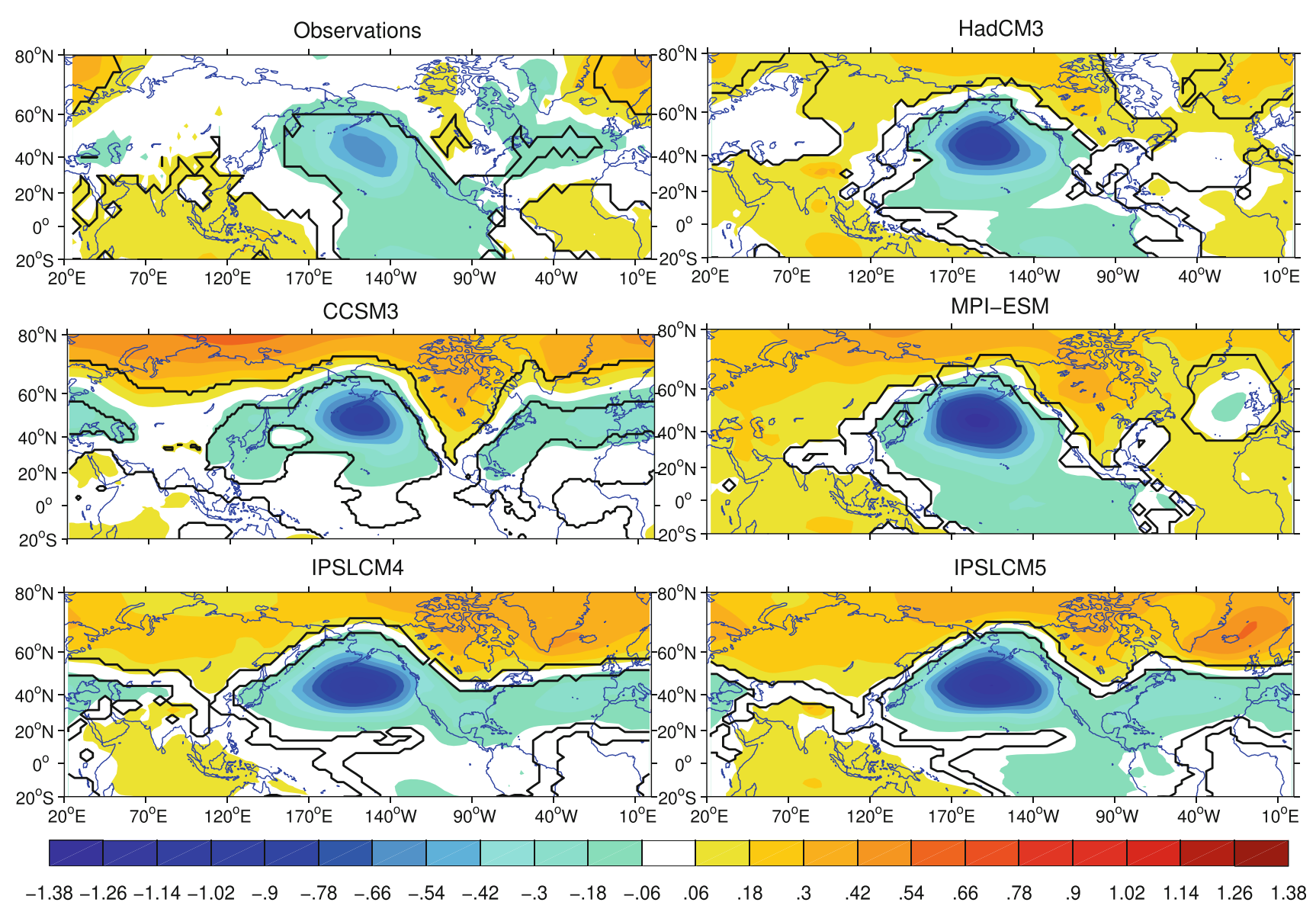

Fig. 9 Regression of low-pass filtered $\left(T_{c}=5 \mathrm{yr}\right.$ ) SLP (in $\mathrm{hPa}$ ) anomalies onto the low-pass filtered PDO. The black contour indicates $10 \%$ significance. Top left observations, top right HadCM3,

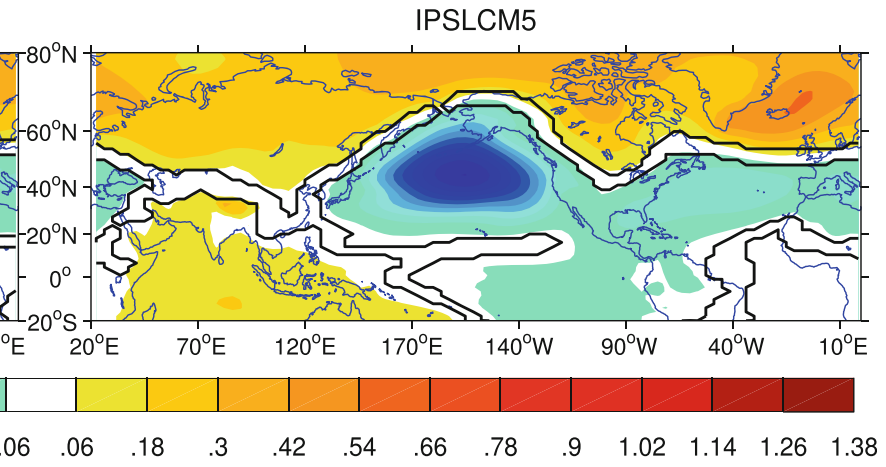

middle left CCSM3, middle right MPI-ESM, bottom left IPSLCM4, bottom right IPSLCM5

most modes have qualitative counterparts, especially those related to ENSO. The ENSO modes (5/6 and 7/8) were subtracted from the SSTs in addition to mode 1, yielding an AMO-GT/EN index that is highly correlated with AMOGT $(r=0.98)$ and, as expected, very similar to the ENSOunrelated AMO found by Compo and Sardeshmukh (2010). The SST pattern (Fig. 11, bottom left) shows a slightly more pronounced cooling in the Indian Ocean, the South Atlantic, and the tropical Pacific.

Mode $2 / 3$ has a multi-decadal period and somewhat resembles the PDO in the North Pacific and the AMO in the North Atlantic, similarly to the second least damped mode found in Newman (2013). Mode 4 is a standing damped mode with large multidecadal changes and strong anomalies in the Pacific and the North Atlantic. The reconstructed low-pass filtered indices from these 2 modes are well correlated at 0.91 with the traditional AMO and at 0.72 with the low-pass filtered PDO, suggesting that these two modes reflect a strong linkage between low frequencies in the Pacific and in the Atlantic. Subtracting additionally these 2 modes from the SSTs caused large changes in the AMO and the associated SST pattern (Fig. 11, bottom right). However, based on the model analysis, this should not be done, and AMO-GT is considered as our best estimate of the AMOC-related part of the AMO.

Interestingly, the mode $2 / 3$ is broadly consistent with Orgeville and Peltier (2007), who suggested that the observed AMO and the low-frequency component of the PDO were signatures of the same oscillation cycle. One cycle of an oscillatory LIM mode is made up of a cosine phase, followed by a sine phase after a quarter period, then a negative cosine phase, and a negative sine phase. The time series of the cosine phase of mode $2 / 3$ is strongly anticorrelated with AMO-trad $(\mathrm{r}=-0.82)$ and its sine phase is correlated, albeit less strongly, with the PDO $(\mathrm{r}=0.49)$. As mode $2 / 3$ has a $48-\mathrm{yr}$ period, the change between a cosine to a sine phase occurs after $12 \mathrm{yr}$, consistent with the lead-lag correlation found by Orgeville and Peltier (2007). However, a better estimate of the observed AMO-PDO correlation should be obtained by removing more efficiently the secular trend before estimating the two indices. When this is done using LIM, the correlation 


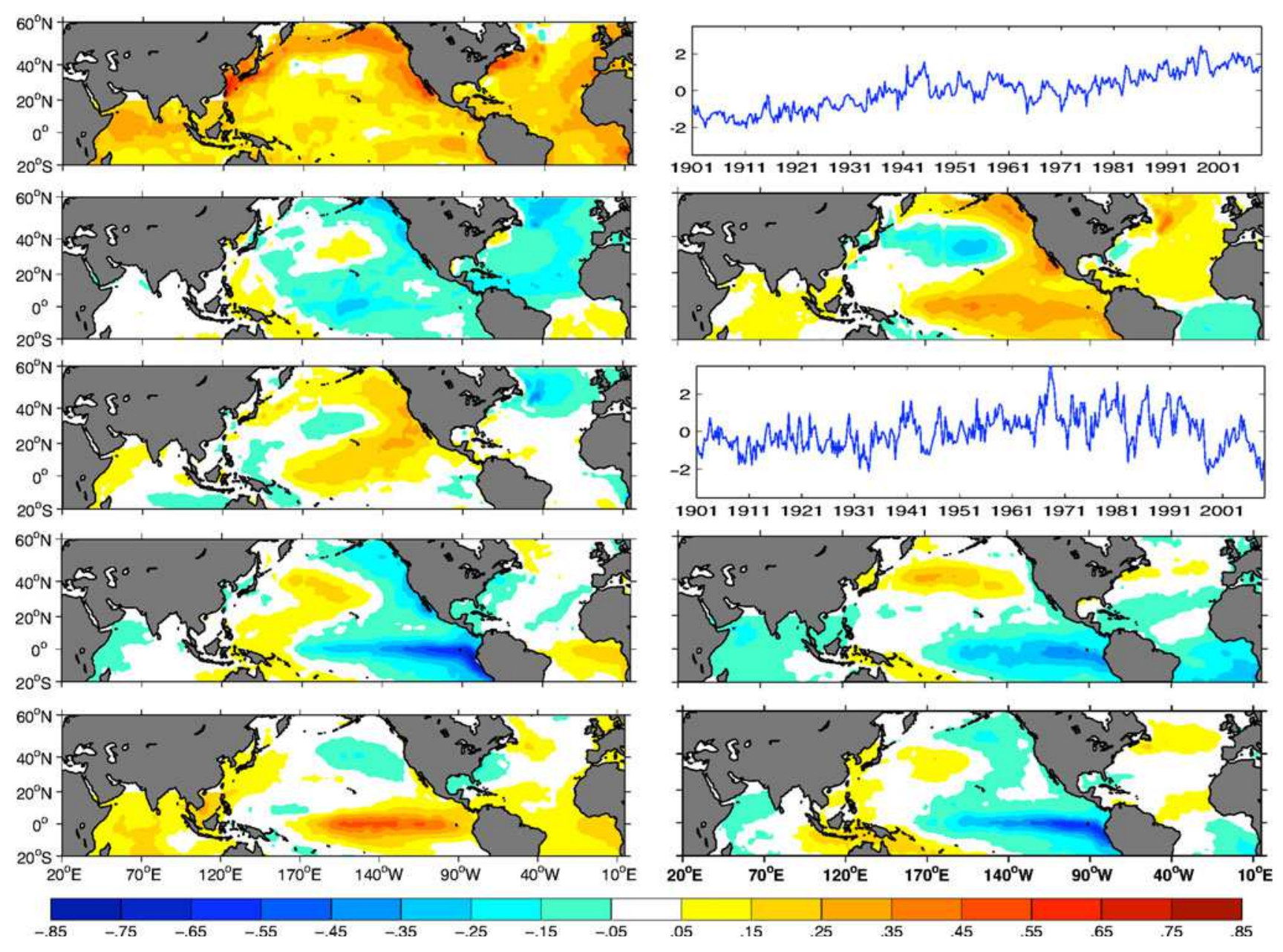

Fig. 10 Normal modes of the deterministic matrix $\boldsymbol{B}$ number, from top to bottom, 1, 2/3, 4, 5/6, and 7/8 for the observed SST. The time series of the non-oscillatory modes is represented
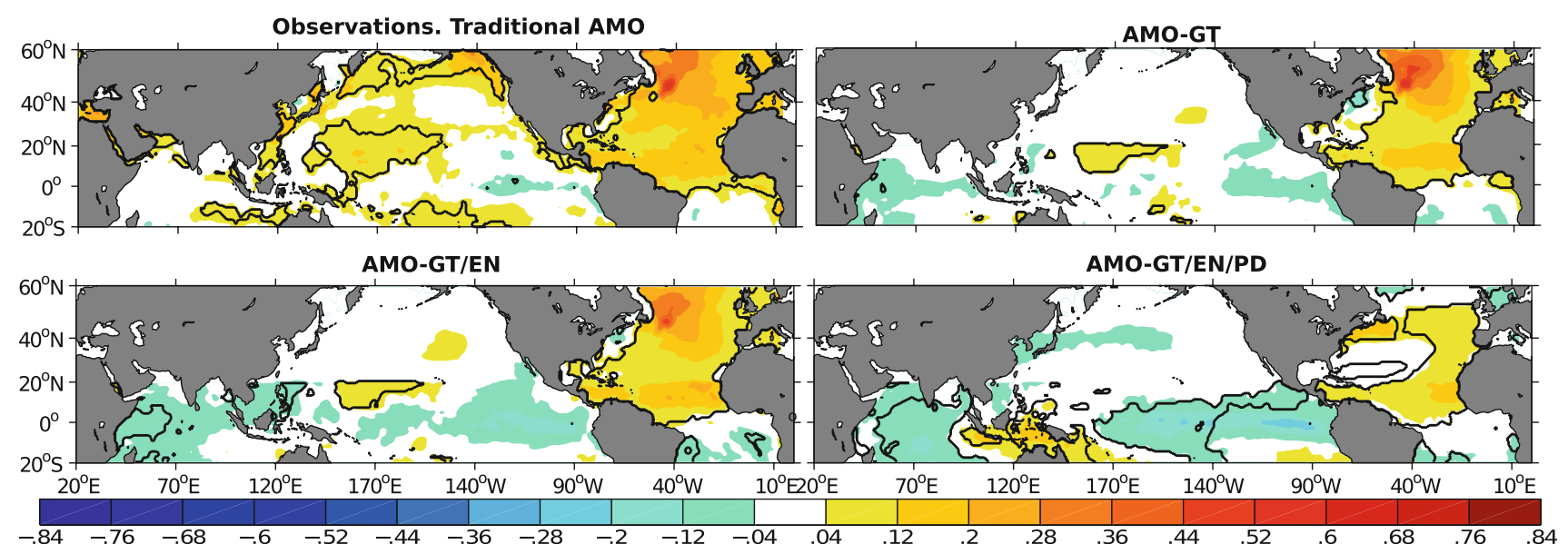

Fig. 11 SST pattern (in K) associated with AMO-trad (top left), AMO-GT (top right), AMO-GT/EN (bottom left), and AMO-GT/EN/PD (bottom right) in the observations. The black contour indicates $5 \%$ significance

between the AMO and the PDO is not changed when the AMO leads or is in phase with the PDO, but it becomes substantially weaker and significance is lost when the PDO leads (Fig. 12). Although statistical significance is difficult to assess in the short records, this suggests a more complex behavior than discussed by Orgeville and Peltier (2007), 
Fig. 12 Correlation between the low-pass filtered $\left(T_{c}=5 \mathrm{yr}\right)$ traditional PDO and AMO indices in the observations (black curve). The red curve corresponds to the correlation when the long-term global SST changes are removed using LIM. Dashed lines indicate $5 \%$ significance

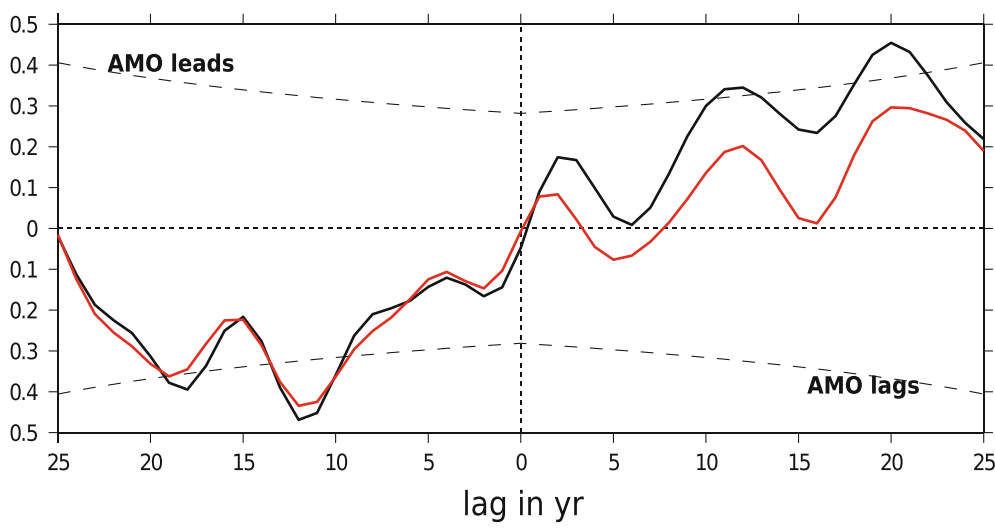

with the AMO playing the leading role. It also emphasizes that a proper removal and the global warming effects has broader applications than just improving the relation between the AMO and the AMOC.

\section{Summary and conclusions}

The link between the AMO and the AMOC was studied in 3 historical and 5 control simulations with several climate models. In all cases, an enhancement of the AMOC is followed by a positive AMO phase, albeit with a modeldependent lag, consistently with previous studies (e.g. Delworth and Mann 2000; Vellinga and Wu 2004; Knight et al. 2005). However, the AMOC-AMO correlation was much weaker in the historical simulations with IPSLCM5 and, to a lesser extent, HadCM3 when the influence of external and anthropogenic forcing was removed by a linear trend, as commonly done. A higher correlation was obtained when removing the global mean SST before estimating the AMO, and an even better one by removing a regression on this global mean, as already shown by Ting et al. (2009).

The LIM approach, which assumes that the SST anomalies are well approximated by a multivariate linear Markov process and decomposes the field into nonorthogonal normal eigenmodes, was then used to remove the global SST signal. Because of the non-orthogonality, LIM should, in principle, distinguish better between modes of variability with different dynamics than, say, regression and EOF analysis. In particular, given a long enough sample, it should be able to separate the long-term anthropogenically and externally forced global SST evolution from intrinsic low-frequency modes of variability that contribute to it, such as the PDO and the AMOC-driven AMO (Meehl and Teng 2012). In the historical simulations that we considered, the global warming tendency was represented by a non-oscillatory mode with the largest or the second largest decay time. When it was removed from the SSTs, the AMO index correlated as well or, in HadCM3, better with the AMOC than when the global signal was removed by regression onto the time series of the global SST average as in Ting et al. (2009). The latter is a simpler method, however, and other historical simulations should be considered for further comparisons. In the observations, the global warming tendency was also represented by a non-oscillatory mode with the largest decay time. When removed from the SSTs, the AMO showed a reduced standard deviation and the recent warming was less pronounced, as in Trenberth and Shea (2006) and Enfield and Cid-Serrano (2010).

The LIM filter has the advantage that it can easily remove other influences from the SST, such as that of ENSO and the low-frequency variability of the Pacific. Although on average, removing ENSO-related empirical eigenmodes modes slightly improved the AMO-AMOC correlation, it lead to conflicting results, increasing it in the historical IPSLCM5 and the MPI-ESM control simulations, but decreasing it the historical HadCM3 simulation, with little effect in other cases. Hence, no firm conclusion can be drawn, and in any case the ENSO influence onto the observed AMO is very weak, as also found by Compo and Sardeshmukh (2010). However, our ENSO modes tend to overestimate the ENSO signal. Solomon and Newman (2012) have shown that ENSO effects could be better removed by using LIM in a different way. This should be tested in the present framework to see if further improvement in the AMOC-AMO relation can be obtained.

As in previous studies, the decadal SST variability of the Pacific was linked to low-frequency variability in the North Atlantic, albeit with time lag. This may be due to the forcing of the AMO, the AMOC, and the Pacific SST by coherent atmospheric patterns, consistent with Müller et al. (2008), who showed that on decadal time scales, the PDO and the NAO were strongly coherent in the observations. It may also be due to the influence of the Pacific variability onto the Atlantic SST, as suggested by Guan and Nigam (2009) based on observations, or it may reflect an influence of the 
Atlantic onto the Pacific, as shown in the observations by Zhang and Delworth (2007). In any case, removing the signal associated with Pacific decadal variability clearly degraded the AMO-AMOC correlation in HadCM3, slightly reduced it in MPI-ESM, the control CCSM3, and the historical IPSLCM5 simulations, while changing little in the other 3 cases. Pending further comparisons, it suggests that the North Pacific links should not be subtracted from the $\mathrm{AMO}$ if its relation to the AMOC is to be optimized.

Although our study shows that LIM is an efficient way to remove global effects from the SSTs before estimating the AMO, our attempt to deconstruct the AMO had limited success and should be improved. It would be worth removing the influence of the local stochastic atmospheric forcing, which drives decadal SST variations because of SST reemergence, gyre variability and other effects, thus affecting the AMO. This might be attempted using LIM, since the atmospheric forcing should enter the white noise forcing $\boldsymbol{F}$ in Eq. (1). However, as stochastic forcing by the $\mathrm{NAO}$ and the East Atlantic Pattern may be important drivers of the AMOC in some climate models (e.g. Eden and Willebrand 2001; Msadek and Frankignoul 2009), removing the local SST response without altering the AMOCdriven one may prove difficult. Interestingly, in a few cases the AMO reconstructed from a single eigenmode better correlated with the AMOC than any other AMO index. In the historical IPSLCM5 simulation, the second normal mode, a non-oscillatory mode with a spectral peak around $80 \mathrm{yr}$, turned out to be better correlated with the AMOC $(r=0.6)$ than AMO-GT/EN. In control simulations with HadCM3 and IPSLCM5, the AMO derived from the oscillatory mode $1 / 2$, which has a period of about $100 \mathrm{yr}$ and large SST anomalies in the North Atlantic, also correlated best with the AMOC ( $r=0.69$ and 0.6 , respectively). However, such mode was not found in the other simulations, and it could not be identified in the observations since the AMOC is not known. Nonetheless, it suggests that the AMOC-AMO relation could be further optimized.

Finally, we emphasize that a proper removal of the global warming effects has broader applications than improving the AMO-AMOC correlation, and eventually reconstructing past AMOC variations from SST proxy. This was illustrated by the relation between the AMO and the PDO. Orgeville and Peltier (2007) had argued that the observed AMO and the multidecadal component of the PDO were two components in phase quadrature of a same oscillation. However, when the secular changes are removed by LIM from both the PDO and the AMO, the correlation remains as strong when the AMO leads the PDO, but decreases when the PDO leads the AMO, suggesting that the AMO plays the leading role in the interbasin connection. This stresses the need to carefully remove the global changes when investigating low-frequency modes.
Acknowledgments The research leading to these results has received funding from the European Community's 7th framework programme (FP7/2007-2013) under grant agreement No. GA212643 (THOR: "Thermohaline Overturning-at Risk", 2008-2012). We thank J. Mignot for useful discussions, and T. DelSole, J. GarciaSerrano, S. Nigam, and the two reviewers for their thoughtful comments.

\section{Appendix 1: Testing the validity of the LIM hypothesis}

If LIM is a good approximation of the system, the matrix $\boldsymbol{B}$ should not depend on the lag $\tau$ used to determine it, ie determining $\boldsymbol{B}$ from $\boldsymbol{C}\left(\tau_{1}\right)=e^{\tau_{1} \boldsymbol{B}}$ or $\boldsymbol{C}\left(\tau_{2}\right)=e^{\tau_{2} \boldsymbol{B}}$, with $\tau_{1} \neq \tau_{2}$ and $C(l)$ the sample covariance matrix of $\mathbf{x}$ (in EOF space), should lead to the same results. Hence, a simple test of the accuracy of the LIM model is to compare $\boldsymbol{B}$ estimated at different lags (tau test, Penland and Sardeshmukh 1995). However, as discussed by Newman (2007), if $\boldsymbol{B}$ can only be determined at one lag because of the Nyquist problem, an alternate test is to verify that the empirically derived matrix $\boldsymbol{B}$ reproduces the sample covariance $\boldsymbol{C}$ at a longer lag $l$ (Winkler et al. 2001). If the model is valid, the covariance matrix at lag $l$ derived from the estimated value of $\mathbf{B}\left(\boldsymbol{C}_{\text {lim }}=e^{l B} \boldsymbol{C}(0)\right)$ should not substantially differ from the sample covariance matrix $\boldsymbol{C}(l)$. This can be evaluated by computing (with $t r$ being the trace):

$d(l)=\frac{\operatorname{tr}\left(\boldsymbol{C}_{\text {lim }}(l)\right)-\operatorname{tr}(\boldsymbol{C}(l))}{\operatorname{tr}(\boldsymbol{C}(l))}$

As it has long been shown that tropical SST anomalies are well represented by LIM (e.g. Penland and Sardeshmukh 1995), we simply compared in two cases $d(l)$ with a distance $d_{r e f}(l)$ obtained by applying LIM only in the tropical strip, retaining the same number of tropical EOF than in the "global" $\boldsymbol{B}$. This was done for the observations and the IPSLCM5 control simulation, using $l=1$ to 30 . In the observations, $d$ ranged between -0.8 and 0.1 and $d_{\text {ref }}(l)$ between -1 and 0.3 , depending on the lag. In the IPSLCM5 control simulation, $d$ was in the interval $[-1.3,1]$ and $d_{r e f}(l)$ in $[-1.5,1.5]$. Thus, in both cases, $d$ and $d_{r e f}(l)$ were of the same order of magnitude, broadly supporting the validity of LIM in the global domain.

\section{Appendix 2: Removing ENSO using LIM}

The non-orthogonality of the $\boldsymbol{B}$ eigenmodes allows a constructive interference of several modes, leading to a transient amplification of the system. Penland and Sardeshmukh (1995) showed that the optimal SST perturbations leading to the maximum amplification of SST 
anomaly variance in the tropical strip evolved into a structure strongly reminiscent of an ENSO event after 7 months. ENSO could then be filtered out by selecting the empirical eigenmodes that most significantly contributed to the growth (Penland and Matrosova 2006). Here, the LIM modes are defined in a broader domain extending from $20^{\circ} \mathrm{S}$ to $70^{\circ} \mathrm{N}$, but we only maximize the amplification of the SST variance in the Tropics $\left(20^{\circ} \mathrm{S}-20^{\circ} \mathrm{N}\right)$, where ENSO is strongest. The tropical SST variance can be measured by the norm vector $\boldsymbol{y}_{\mathrm{N}}=\boldsymbol{y}^{\mathrm{T}} \boldsymbol{N} \boldsymbol{y}$ when $\boldsymbol{N}$ is a positive definite hermitian form (normalized to have unit determinant) defined by $\boldsymbol{N}=(\boldsymbol{W E})^{T}(\boldsymbol{W E})$, where the matrix $\boldsymbol{E}$ of size $(n$, $p$ ) contains the patterns of the $p$ retained EOF restricted to the $n$ grid points of the Tropics, and $\boldsymbol{W}$ is a matrix of area weighting, which takes into account the earth curvature. The amplification $\mu$ of the system over a time $\tau$ is then defined by

$$
\mu(\tau)=\frac{\left\|\boldsymbol{x}(\tau)_{N}^{2}\right\|}{\left\|\boldsymbol{x}(0)_{N}^{2}\right\|}=\frac{\boldsymbol{x}(\tau)^{T} \boldsymbol{N} \boldsymbol{x}(\tau)}{\boldsymbol{x}(0)^{T} \boldsymbol{x}(0)}=\frac{\boldsymbol{x}(0)^{T} \boldsymbol{G}(\tau)^{\boldsymbol{T}} \boldsymbol{N} \boldsymbol{G}(\tau) \boldsymbol{x}(0)}{\boldsymbol{x}(0)^{T} \boldsymbol{x}(0)}
$$

We thus search for the initial structure with small SST anomaly variance in the entire domain leading to the largest SST anomaly variance in the tropical strip.
The optimal initial condition $\boldsymbol{x}(0)$ that maximizes $\|\boldsymbol{x}(\tau)\|_{N}^{2}$ subject to $\boldsymbol{x}(0)$ having unit norm under the $L_{2}$ norm (ie $\boldsymbol{x}(0)^{T} \boldsymbol{x}(0)=1$ ) is given by

$\max _{\boldsymbol{x}(0)}\left\{\boldsymbol{x}(0)^{T} \boldsymbol{G}(\tau)^{\boldsymbol{T}} \boldsymbol{N} \boldsymbol{G}(\tau) \boldsymbol{x}(0)+\gamma \boldsymbol{x}(0)^{T} \boldsymbol{x}(0)\right\}$

which leads to the generalized eigenvalue problem:

$\boldsymbol{G}(\tau)^{\boldsymbol{T}} \boldsymbol{N} \boldsymbol{G}(\tau) \boldsymbol{x}(0)=\gamma \boldsymbol{x}(0)$

with the optimal initial structure normalized such as $\boldsymbol{x}(0)^{T} \boldsymbol{x}(0)=1$. The eigenvector $\varphi 1(\tau)$ of (8) associated with the largest eigenvalue $\beta_{1}(\tau)$ is the initial spatial structure leading to the maximum amplification after a time $\tau$. The function $\beta_{1}(\tau)$, called the maximum amplification curve, quantifies the maximum growth possible over an interval $\tau$ in the absence of forcing. The optimal initial structure is given by $x(0)=\varphi_{1}\left(\tau_{m}\right)$ with $\tau_{m}=\arg$ $\max \left(\varphi_{1}(\tau)\right)$, leading to the maximum amplification $x\left(\tau_{\mathrm{m}}\right)=G\left(\tau_{m}\right) x(0)=G\left(\tau_{m}\right) \varphi_{1}\left(\tau_{m}\right)$ in $\tau_{m}$ months.

In all models, the optimal initial structure shows strong SST anomalies in the eastern equatorial Pacific with a maximum generally found between $110^{\circ}$ and $130^{\circ} \mathrm{W}$, as in the observations. This is illustrated for HadCM3 in Fig. 13, where hints of the seasonal footprinting mechanism (Vimont et al. 2003) can be seen in the eastern subtropical
Fig. 13 Maximum Amplification curve (top left) and projection of normal modes onto the optimal initial structure (top right) in HadCM3. Optimal initial structure (middle) leading to maximum amplification (bottom) of SST variance in the tropical strip
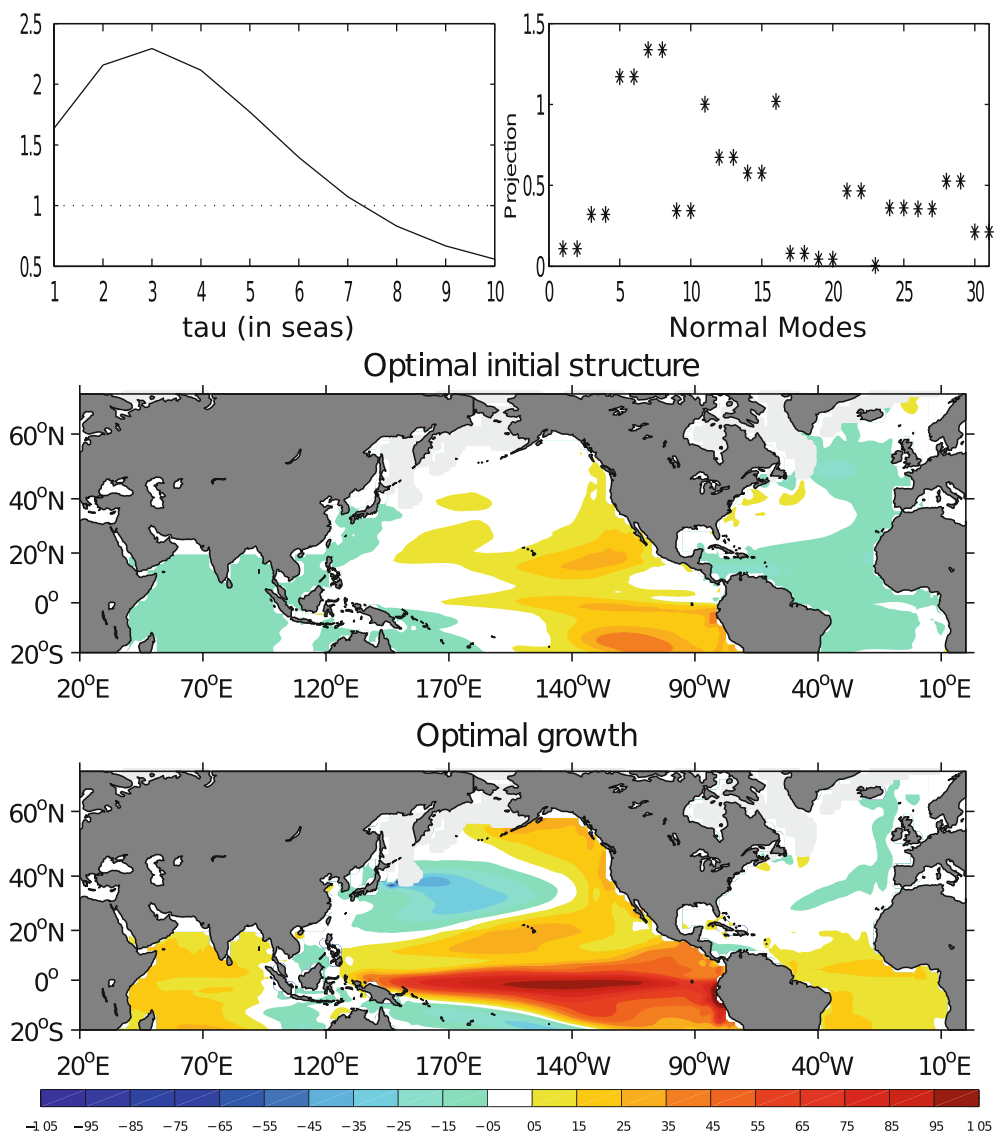
Pacific. The optimal growth occurs after 6 or 9 months depending on the model, showing very large SST anomalies spanning the tropical Pacific and a horseshoe pattern in the North Pacific, reminiscent of a mature ENSO event.

The contribution from each eigenmode $\boldsymbol{u}_{i}$ of $\boldsymbol{B}$ to the optimal initial structure can be estimated by the magnitude of its projection onto the corresponding modal adjoint, the eigenvector $\boldsymbol{v}_{i}$ of $\boldsymbol{B}^{T}$, which has the same eigenvalue as $\boldsymbol{u}_{i}$. Eigenmodes corresponding to global SST changes and Pacific decadal changes may contribute to the optimal initial structure, but cannot be considered as ENSO modes. Hence, modes having a larger period than $8 \mathrm{yr}$ or a decay time larger than 24 months were not classified as ENSO modes. As discussed in Penland and Matrosova (2006), the identification of ENSO modes is somewhat subjective, and this holds for the Pacific decadal modes. Choosing too many modes may add noise in the North Atlantic SSTs and include signals that are involved in the link between the $\mathrm{AMO}$ and the AMOC, while choosing too few modes may miss a significant part of the ENSO signal.

In all simulations and in the observations, the reconstructed ENSO indices correlated well with the traditional Nino 1.2 and Nino 3.4 indices, $r$ ranging between about 0.7 and 0.9 , and the associated SST patterns were very similar, although their amplitude was generally overestimated (see Marini 2011 for more details). Adding more oscillatory modes fitting our criteria to the ENSO subset leads to realistic amplitudes, but more noisy patterns, so that the link between the ENSO-unrelated AMO and the AMOC was deteriorated. This supports our choice of a limited number of ENSO modes.

\section{References}

Alexander M, Bladé I, Newman M, Lanzante J, Lau N, Scott J (2002) The atmospheric bridge: the influence of ENSO teleconnections on air-sea interaction over the global oceans. J Clim 15:2205-2231

Allan R, Ansell T (2006) A new globally complete monthly historical gridded mean sea level pressure dataset (hadSLP2): 1850-2004. J Clim 19:5816-5842

Booth BB, Dunstone NJ, Halloran PR, Andrews T, Bellouin N (2012) Aerosols implicated as a prime driver of twentieth-century North Atlantic climate variability. Nature 484:228-232

Bretherton C, Widmann M, Dymnikov V, Wallace J, Bladé I (1999) The effective number of spatial degrees of freedom of a timevarying field. J Clim 12:1990-2009

Brönnimann S (2007) Impact of El Niño-Southern Oscillation on European climate. Rev Geophys 45:RG3003

Collins W, Bitz C, Blackmon M, Bonan G, Bretherton C, Carton J, Chang P, Doney S, Hack J, Henderson T et al (2006) The community climate system model version 3 (CCSM3). J Clim 19:2122-2143

Compo G, Sardeshmukh P (2010) Removing ENSO-related variations from the climate record. J Clim 23:1957-1978. doi:10.1175/ 2009JCLI2735.1
DelSole T, Tippett MK, Shukla J (2011) A significant component of unforced multidecadal variability in the recent acceleration of global warming. J Clim 24:909-926

Delworth T, Mann M (2000) Observed and simulated multidecadal variability in the northern hemisphere. Clim Dyn 16:661-676

Delworth T, Manabe S, Stouffer R (1993) Interdecadal variations of the thermohaline circulation in a coupled ocean-atmosphere model. J Clim 6:1993-2011

Deser C, Alexander MA, Xie S-P, Phillips AS (2010) Sea surface temperature variability: patterns and mechanisms. Annual Review of Marine Science 2:115-143

Deshayes J, Frankignoul C (2008) Simulated variability of the circulation in the North Atlantic from 1953 to 2003. J Clim 21:4919-4933

Dima M, Lohmann G (2007) A hemispheric mechanism for the Atlantic Multidecadal Oscillation. J Clim 20:2706-2719

Dong B, Sutton R (2001) The dominant mechanisms of variability in Atlantic Ocean Heat Transport in a Coupled Ocean-Atmosphere GCM. Geophys Res Lett 28:2445-2448

Dong B, Sutton R (2005) Mechanism of Interdecadal thermohaline circulation variability in a Coupled Ocean-Atmosphere GCM. J Clim 18:1117-1135

Drijfhout S, Van Oldenborgh GJ, Cimatoribus A (2012) Is a Decline of AMOC Causing the Warming Hole above the North Atlantic in Observed and Modeled Warming Patterns? J Clim 25:83738379

Dufresne JL et al (2013) Climate change projections using the IPSLCM5 Earth System Model: from CMIP3 to CMIP5. Clim Dyn. doi: 10.1007/s00382-012-1636-1

Eden C, Willebrand J (2001) Mechanism of interannual to decadal variability of the North Atlantlic Circulation. J Clim 14:22662280

Enfield D, Cid-Serrano L (2010) Secular and multidecadal warmings in the North Atlantic and their relationships with major hurricane activity. Int J Climatol 30:174-184

Enfield DB, Mestas-Nunez A (1999) Multiscale variabilities in global sea surface temperatures and their relationships with tropospheric climate patterns. J Clim 12:2719-2733

Enfield D, Mestas-Nunez A, Trimble P et al (2001) The Atlantic Multidecadal Oscillation and its relation to rainfall and river flows in the continental US. Geophys Res Lett 28:2077-2080

Escudier R, Mignot J, Swingedouw D (2013) A 20-year coupled ocean-sea ice-atmosphere variability mode in the North Atlantic in an AOGCM. Clim Dyn 40:619-636

Furtado J, di Lorenzo E, Schneider N, Bond N (2011) North Pacific decadal variability and climate change in the IPCC AR4 models. J Clim 24:3049-3067

Gastineau G, D'Andrea F, Frankignoul C (2013) Atmospheric response to the North Atlantic Ocean variability on seasonal to decadal time scales. Clim Dyn 40:2311-2330

Gordon C, Cooper C, Senior C, Banks H, Gregory J, Johns T, Mitchell J, Wood R (2000) The simulation of SST, sea ice extents and ocean heat transports in a version of the Hadley Centre coupled model without flux adjustments. Clim Dyn 16:147-168. doi:10.1007/s003820050010

Guan B, Nigam S (2009) Analysis of Atlantic SST Variability Factoring Interbasin Links and the Secular Trend: clarified Structure of the Atlantic Multidecadal Oscillation. J Clim 22: $4228-4240$

Hawkins E, Sutton R (2009) Decadal predictability of the Atlantic Ocean in a coupled GCM: forecast skill and optimal perturbations using linear inverse modeling. J Clim 22:3960-3978

Hawkins E, Robson J, Sutton R, Smith D, Keenlyside N (2011) Evaluating the potential for statistical decadal predictions of sea surface temperatures with a perfect model approach. Clim Dyn $37: 2495-2509$ 
Jungclaus J, Lorenz S, Timmreck C, Reick C, Brovkin V, Six K, Segschneider J, Giorgetta M, Crowley T, Pongratz J et al (2010) Climate and carbon-cycle variability over the last millennium. Climate of the Past 6:723-737

Kerr R (2000) A North Atlantic climate pacemaker for the centuries. Science 288:1984-1985

Knight J, Allan R, Folland C, Vellinga M, Mann M (2005) A signature of persistent natural thermohaline circulation cycles in observed climate. Geophys Res Lett 32:L20708. doi:10.1029/ 2005GL024233

Knight J, Folland C, Scaife A (2006) Climate impacts of the Atlantic Multidecadal Oscillation. Geophys Res Lett 33:L17706

Kushnir Y (1994) Interdecadal variations in North Atlantic sea surface temperature and associated atmospheric conditions. J Clim 7:141-157

Kwon Y, Frankignoul C (2012) Stochastically-driven multidecadal variability of the Atlantic meridional overturning circulation in CCSM3. Clim Dyn 38:859-876

Latif M, Roeckner E, Botzet M, Esch M, Haak H, Hagemann S, Jungclaus J, Legutke S, Marsland S, Mikolajewicz U (2004) Reconstructing, monitoring, and predicting multidecadal-scale changes in the North Atlantic thermohaline circulation with the sea surface temperature. J Clim 17:1605-1614

Li C, Wu L, Wang Q, Qu L, Zhang L (2009) An intimate coupling of ocean-atmospheric interaction over the extratropical North Atlantic and Pacific. Clim Dyn 32:753-765

Mann ME et al (2009) Global signatures and dynamical origins of the Little Ice Age and Medieval Climate Anomaly. Science 326: $1256-1260$

Marini (2011) Study of the causes and effects of the Atlantic Meridional Overturning Circulation. $\mathrm{PhD}$ thesis, Université Pierre et Marie Curie, Paris 6

Marti O et al (2010) Key features of the IPSL ocean atmosphere model and its sensitivity to atmospheric resolution. Clim Dyn 34:1-26

Matei D, Baehr J, Jungclaus J, Haak H, Müller W, Marotzke J (2012) Multiyear prediction of monthly mean Atlantic meridional overturning circulation at $26.5^{\circ} \mathrm{N}$. Science $335: 76-79$

Meehl GA, Teng H (2012) Case studies for initialized decadal hindcasts and predictions for the Pacific region. Geophys Res Lett 39:L22705

Meehl G, Covey C, Delworth T, Latif M, McAvaney B, Mitchell J, Stouffer R, Taylor K (2007) The WCRP CMIP3 multi-model dataset: a new era in climate change research. Bull Am Meteorol Soc 88:1383-1394

Mignot J, Ganopolski A, Levermann A (2007) Atlantic subsurface temperatures: response to a shutdown of the overturning circulation and consequences for its recovery. J Clim 20:48844898

Msadek R, Frankignoul C (2009) Atlantic multidecadal oceanic variability and its influence on the atmosphere in a climate model. Clim Dyn 33:45-62

Msadek R, Dixon K, Delworth T, Hurlin W (2010) Assessing the predictability of the Atlantic meridional overturning circulation and associated fingerprints. Geophys Res Lett 37:L19608

Müller W, Frankignoul C, Chouaib N (2008) Observed decadal tropical Pacific-North Atlantic teleconnections. Geophys Res Lett 35:L24810

Newman M (2007) Interannual to decadal predictability of tropical and North Pacific sea surface temperatures. J Clim 20:2333-2356

Newman M (2013) An empirical benchmark for decadal forecasts of global surface temperature anomalies. J Clim
Newman M, Sardeshmuck PA (2008) Tropical and stratospheric influences on extratropical short-term climate variability. J. Climate 21:4326-4347

Newman M, Alexander MA, Scott JD (2011) An empirical model of tropical ocean dynamics. Clim Dyn 37:1823-1841

Nigam S, Guan B, Ruiz-Barradas A (2011) Key role of the Atlantic Multidecadal Oscillation in 20th century drought and wet periods over the great plains. Geophys Res Lett 38:L16713

Orgeville M, Peltier W (2007) On the Pacific Decadal Oscillation and the Atlantic Multidecadal Oscillation: might they be related? Geophys Res Lett 34:L23705

Oshima K, Tanimoto Y (2009) An evaluation of reproducibility of the Pacific Decadal Oscillation in the CMIP3 simulations. J Meteorol Soc Jpn 87:755-770

Otterå OH, Bentsen M, Drange H, Suo L (2010) External forcing as a metronome for Atlantic multidecadal variability. Nat Geosci 3:688-694

Overland J, Wang M (2007) Future climate of the North Pacific Ocean. Eos, Transactions American Geophysical Union 88:178-182

Penland C, Matrosova L (1994) A Balance Condition for Stochastic Numerical Models with Application to the ENSO. J Clim 7:1352-1372

Penland C, Matrosova L (2006) Studies of El Niño and Interdecadal Variability in Tropical Sea Surface Temperatures Using a Nonnormal Filter. J Clim 19:5796-5815

Penland C, Sardeshmukh P (1995) The Optimal Growth of SST Anomalies. J Clim 8:1999-2024

Rayner NA, Parker D, Horton E, Folland C, Alexander L, Rowell D, Kent E, Kaplan A (2003) Global analyses of sea surface temperature, sea ice, and night marine air temperature since the late nineteenth century. J Geophys Res Atmos 108:4407. doi: 10.1029/2002JD002670

Solomon A, Newman M (2012) Reconciling disparate twentiethcentury indo-pacific ocean temperature trends in the instrumental record. Nature Climate Change 2:691-699

Sutton R, Hodson D (2005) Atlantic ocean forcing of American and European summer climate. Science 309:115-118

Taylor KE, Stouffer RJ, Meehl GA (2012) An overview of CMIP5 and the experiment design. Bull Am Meteorol Soc 93:485-498

Ting M, Kushnir Y, Seager R, Li C (2009) Forced and internal twentieth-century SST trends in the North Atlantic. J Clim 22:1469-1481

Trenberth K, Shea D (2006) Atlantic hurricanes and natural variability in 2005. Geophys Res Lett 33:L12704

Vellinga M, Wu P (2004) Low-latitude freshwater influence on centennial variability of the Atlantic thermohaline circulation. J Clim 17:4498-4511. doi:10.1175/3219.1

Vimont D, Wallace J, Battisti D (2003) The seasonal footprinting mechanism in the Pacific: implications for ENSO. J Clim $16: 2668-2675$

Winkler C, Newman M, Sardeshmukh P (2001) A linear model of wintertime low-frequency variability. Part 1: formulation and forecast skill. J Clim 14:4474-4494

Zanna L (2012) Forecast skill and predictability of observed Atlantic sea surface temperatures. J Clim 25:5047-5056

Zanna L, Tziperman E (2005) Nonnormal amplification of the thermohaline circulation. J Phys Oceanogr 35:1593-1605

Zhang R, Delworth T (2007) Impact of the Atlantic Multidecadal Oscillation on North Pacific climate variability. Geophys Res Lett 34:L23708. doi:10.1029/2007GL031601 